UMR 5824

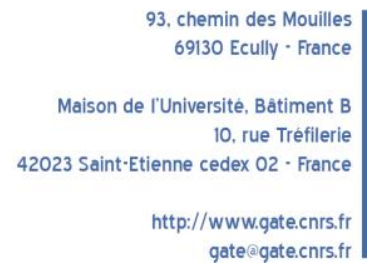

WP 1933 - November 2019

\title{
The Old-Age Security Motive for Fertility: Evidence from the Extension of Social Pensions in Namibia
}

\author{
Pauline Rossi, Mathilde Godard
}

\begin{abstract}
:
The old-age security motive for fertility postulates that people's needs for old-age support raise the demand for children. We test this widespread idea using the extension of social pensions in Namibia during the nineties. The reform eliminated inequalities in pension coverage and benefit across regions and ethnic groups. Combining differences in pre-reform pensions and differences in exposure across cohorts, we show that pensions substantially reduce fertility, especially in late reproductive life. This article provides the first quasi-experimental quantification of the old-age security motive. The results suggest that improving social protection for the elderly could go a long way in fostering fertility decline in Sub-Saharan Africa.
\end{abstract}

\section{Keywords:}

Fertility, Old-age pensions, Social security, Africa, Difference-in-differences

JEL codes:

D15, H55, 138, J13, 015, O55

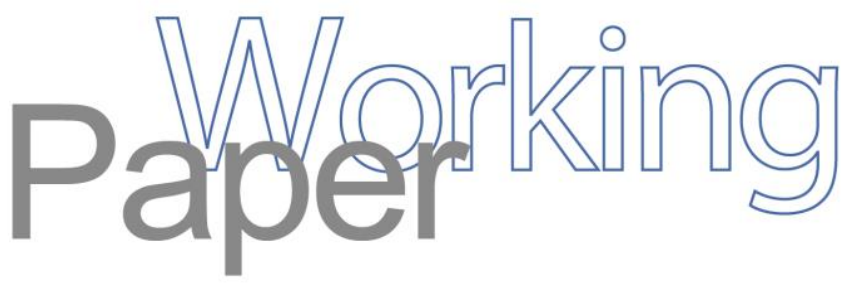




\title{
The Old-Age Security Motive for Fertility: Evidence from the Extension of Social Pensions in Namibia
}

\author{
Pauline Rossi and Mathilde GODARD *
}

September 2019

\begin{abstract}
The old-age security motive for fertility postulates that people's needs for old-age support raise the demand for children. We test this widespread idea using the extension of social pensions in Namibia during the nineties. The reform eliminated inequalities in pension coverage and benefit across regions and ethnic groups. Combining differences in pre-reform pensions and differences in exposure across cohorts, we show that pensions substantially reduce fertility, especially in late reproductive life. This article provides the first quasi-experimental quantification of the old-age security motive. The results suggest that improving social protection for the elderly could go a long way in fostering fertility decline in Sub-Saharan Africa.
\end{abstract}

Keywords: Fertility, Old-age pensions, Social security, Africa, Difference-in-differences.

JEL Codes: D15, H55, I38, J13, O15, O55.

\footnotetext{
${ }^{*}$ Rossi (corresponding author): University of Amsterdam, Tinbergen Institute and CEPR; Roeterstraat 11, 1018WB Amsterdam, the Netherlands, p.rossi@uva.nl. Godard: University of Lyon, CNRS, GATE UMR 5824, F-69130 Ecully, France. We are grateful to Selma Shifotoka, Fransina Amutenya and, above all Alwis Weerasinghe, for their invaluable help in accessing and understanding the NHIES data, and to Maria Iocco Barias and Ece Kafali for excellent research assistance. This paper was inspired by discussions with Pascaline Dupas, Seema Jayachandran, Adriana Lleras-Muney, and Manisha Shah. For their helpful comments, we thank Roel Beetsma, Irene Botosaru, Thomas Buser, Clement de Chaisemartin, Lucie Gadenne, Giacomo de Giorgi, Xavier d'Haultfoeuille, Clement Imbert, Wendy Janssens, Robert Jensen, Clement Joubert, Bas van der Klaauw, Sylvie Lambert, Gianmarco Leon, Joan Monras, Hessel Oosterbeek, Menno Pradhan, Maria Petrova, Erik Plug, Roland Rathelot, Thijs van Rens, Mark Rosenzweig, Anita Schwarz, Victor Sulla, Alessandro Tarozzi, Maxime To, Sofia Trommlerova, Paola Villar, and participants to seminars at University of Amsterdam, Pompeu-Fabra, Warwick, ILO, and the World Bank. We acknowledge financial support from CEPREMAP. Rossi acknowledges the support from the Netherlands Organisation for Scientific Research (NWO) through the individual starting grant Veni 451-17-012.
} 


\section{Introduction}

This article connects two debates on Africa's development: how to foster fertility decline, and whether governments should provide universal old-age pensions. Currently, both debates are discussed in isolation. This is surprising since the idea that people have children partly in order to secure old-age support is a longstanding hypothesis in social sciences (Nugent 1985). We lack credible evidence on the importance of this old-age security motive for fertility, though. Are the needs for old-age support a first-order or a negligible driver of fertility?

We exploit the extension of social pensions in Namibia in the nineties to study this question. The reform took place after the end of the apartheid and eliminated inequalities in coverage across regions and inequalities in benefits across ethnic groups. Restricting our attention to the Black population, we combine the variation in pre-reform pensions with the variation in exposure across cohorts in a difference-in-differences framework. We examine the number as well as the timing of births, and find that social pensions substantially reduce fertility, especially after age 30. Our estimates predict that completed fertility could be reduced by at least one to two children in other Sub-Saharan African countries if they implemented a pension system similar to the ones currently in place in Southern Africa.

The relationship between pensions and fertility is of interest for demographers, economists, and policy makers. In theory, the old-age security motive for fertility can be important under some conditions: (i) there is no better way to secure well-being in old-age than relying on children; and (ii) the quality-quantity trade-off is limited so that more children do provide more support. Whether these conditions hold in practice and influence reproductive behaviors is an open empirical question. In a recent review article, Piggott and Woodland (2016) conclude that "The empirical evidence supporting this hypothesis is surprisingly scarce. [...] More research is certainly needed to understand how much the growing availability of substitutes for old-age security affects the decline in the demand for children".

Quantifying the strength of the old-age security motive is challenging. Field experiments are difficult to implement due to the lag between the time when people make their reproductive decisions, and the time when they receive their pensions. Young couples would have to trust that money will actually be paid twenty to forty years later, and it would take long and be costly to build such a trust. A more feasible option is exploiting the introduction of real pension systems as natural experiments, although this raises simultaneity and reverse causality issues. Indeed, the introduction of old-age pensions is often part of a broader structural change in the economy and in the society, which makes it difficult to isolate the impact of pensions. Moreover, the fall in fertility can precede and drive the demand for social security. 
These issues are salient in before-after comparisons and cross-country comparisons; they can be mitigated by tracking the extension of pensions to different parts of a national population.

In Sub-Saharan Africa, only eight countries currently have well-developed social pension systems, with a coverage between two thirds and universal, and benefits between 15 and $20 \%$ of the average income. ${ }^{1}$ As shown by Figure A.1 in Appendix, these countries turn out to have much lower fertility rates than the rest of the continent: three compared to five children per woman. To study whether this correlation partly captures a causal effect, the most interesting settings are South Africa and Namibia, because there is variation in the inclusiveness of pensions across periods, regions and ethnic groups. Under the apartheid, the pension system was characterized by high inequalities in generosity and in access, not only between Whites and Blacks but also within the Black population. De jure, benefits were defined at the ethnic group level (e.g. Damara, Nama, Herero, Owambo etc); de facto, the administration was decentralized at the regional level and left behind substantial shares of eligible people, particularly in rural areas. After the apartheid, the system was extended to ensure that everyone receives the same social pension: equal benefits and quasi-universal coverage were achieved by the end of the nineties.

We argue that the Namibian context provides a clean difference-in-differences design. First, we can exploit information from the national Household Income and Expenditure Survey conducted in 1993-94 to construct a measure of initial pensions that varies at the regional and ethnicity levels within the Black population. This is not feasible in South Africa. ${ }^{2}$ Second, four waves of the Demographic and Health Surveys collected between 1992 and 2013 provide retrospective information on birth histories of relevant cohorts. We have a long time window to study the whole reproductive period of women, and analyze the timing and the total number of births. The extension was implemented in just a few years during the mid-nineties. This sudden change is predicted to generate a marked pattern across years and cohorts that can be distinguished from a secular decline. Third, we are able to control for many potential confounding factors. We show that omitted variables tend to generate an underestimation bias in this context, because people previously disadvantaged by the pension system benefited less from other socio-economic changes. Last, the extension was

\footnotetext{
${ }^{1}$ These are all Southern African countries: South Africa (since 1928), Namibia (1949) Botswana (1996), Lesotho (2004), and Swaziland (2005), and small islands: Mauritius (1950), Seychelles (1979), and Cape Verde (2006). The vast majority of African countries have no social pension system at all. See Figure A.2 in Appendix for more details.

${ }^{2}$ The same household survey was carried out in both countries in 1993-94. At that time, the extension had just started in Namibia, whereas it had already been implemented in South Africa so there was no variation in pensions anymore. Earlier surveys exclude Black homelands and are therefore not representative.
} 
driven by equity motives, with the explicit goal of granting the same rights to everyone. An extension driven by economic motives and targeting vulnerable groups could have raised concerns about reverse causality.

We find that before the reform, people disadvantaged by the pension system had more children; the difference in birth rates was particularly strong in the second half of women's reproductive life, between ages 30 and 45. The equalization of pensions is followed by a fast convergence in the number of births. The convergence starts precisely when the reform is announced and was completed within a decade. Cross-cohort patterns coincide with exposure to the new pension system during the late reproductive years. We check that these results are not driven by specific regions or ethnic groups, and do not reflect composition effects. Changes in age at last birth, ideal family size, and childbearing intention confirm that the main mechanism is stopping rather than starting or spacing. We further examine female labor supply and household income, and conclude that the negative impact of pensions on fertility does not operate through these channels, but rather through the old-age insurance motive. Our estimates predict that improving pension coverage from one third to two thirds, and benefits from $18 \%$ to $25 \%$ of average income, reduces completed fertility by an order of magnitude of one to two children. We provide evidence of non-linearities suggesting that introducing - even more than expanding - social protection for the elderly in other SubSaharan African countries could lead to a substantial, rapid decline in fertility.

Our results contribute to two strands of policy discussions. First, old-age pensions are rarely included in the policy tools to reduce fertility. To achieve their goal of containing population growth, African governments target an improvement in birth control through better access to contraceptives and female empowerment. The assumption is that people have more children than what they want. ${ }^{3}$ Our analysis suggests that exploring why people want many children and what can be done to change these incentives could help renewing population policies. Second, the impact on fertility is not mentioned in the discussions on pensions. Social protection for the elderly figures prominently in the global strategy to fight poverty and inequalities. ${ }^{4}$ When weighing the gains in terms of protection and redistribution against the fiscal costs, decision makers overlook fertility responses. Based on

\footnotetext{
${ }^{3}$ See for example United Nations (2013) or United Nations (2015) recommending to "invest in reproductive health and family planning, particularly in the least developed countries, so that women and couples can achieve their desired family size".

${ }^{4}$ Old-age social pensions are highlighted as a special theme in the 2018 edition of the State of Social Safety Nets (World Bank 2018) and monitored as a key indicator to reach the Sustainable Development Goal target 1.3 calling for the implementation of appropriate social protection systems and measures (International Labour Organization 2018).
} 
this article, it can be argued that including these responses may change the conclusions since they potentially affect both benefits and costs, through the intergenerational transmission of poverty and the evolution of dependency ratios.

The outline of the paper is as follows. Section 2 provides interdisciplinary background on the relationship between pensions and fertility. Section 3 describes the Namibian pension system and the historical context. Section 4 presents the data and important descriptive statistics. Section 5 sets up the empirical strategy. Section 6 reports the results and the robustness tests. Section 7 discusses policy implications and Section 8 concludes.

\section{Literature}

The relationship between old-age pensions and fertility has been discussed by demographers, macro-economists and micro-economists. However, only a handful of studies try to provide empirical evidence on the importance of the old-age security motive for fertility.

The seminal conceptual paper seems to be Leibenstein (1957) and the idea is further developed in Caldwell (1978), Caldwell (1982), and Nugent (1985). In the eighties, old-age security was considered as the least thoroughly analyzed motive for fertility and quantifying its actual importance was a main challenge to demographic research (Stolnitz 1983). According to recent literature reviews, this challenge was not taken up (Piggott and Woodland 2016). Reviewing the potential drivers of the historical fertility transition, Guinnane (2011) mentions old-age support and argues that "the use of certain theoretical ideas has also led some to believe that the relevant propositions have actually been tested in historical contexts, when that is unfortunately often not the case". In particular, he reports no conclusive empirical evidence from comparisons between the timing of social insurance's rise and the timing of fertility transitions in Europe.

In macro-economics, a large literature is interested in the relationship between old-age pensions and fertility, but most articles study the opposite causal link: what is the impact of low fertility on the sustainability of pension systems? A smaller literature looks at our relationship of interest using either cross-country or before-after comparisons. These articles consistently find that larger social security systems are associated with fewer children (see review in Boldrin, Nardi, and Jones (2015)). One way to go beyond correlations is estimating over-lapping generation models with cross-country panel data. The difficulty is that different assumptions on the direction of intergenerational transfers lead to different conclusions (Boldrin, Nardi, and Jones 2015). In the Boldrin and Jones (2002) model, where transfers go 
from children to parents, social pensions explain over $80 \%$ of the variation in fertility across the world. In contrast, pensions explain very little in the Barro and Becker (1989) model, where transfers go from parents to children.

In the applied microeconomics literature, most research looks at the substitution between formal and informal old-age insurance, assuming that fertility is exogenous. Papers have shown that children do support parents in old-age (Hoddinott 1992, Oliveira 2016), especially if the pension system is absent or failing (Cox and Jimenez 1992, Juarez 2009, Cai, Giles, and Meng 2006). In South Africa, Jensen (2003) finds evidence of crowding-out: transfers by children are reduced by $0.25-0.30$ rand for each rand paid by the old-age pension system. Furthermore, Bau (2019) further shows that intergenerational co-residence practices tend to decline when formal pensions become available. Last, parents change their old-age arrangements if they have fewer kids, especially fewer sons (Ebenstein and Leung 2010, Banerjee, Meng, Porzio, and Qian 2014).

As far as we know, only three papers study whether parents change their fertility behaviors in anticipation of children's support. One experimental article investigates the No Birth Bonus Scheme in South India (Ridker 1980). In the experiment, women received money on a bank account that was blocked until retirement if they had no child during the year. The author finds a large effect, but there are many flaws with the design, ${ }^{5}$ and the experiment is first and foremost a test of financial incentives rather than old-age security needs. Two quasiexperimental studies have used the introduction of pensions in rural Mexico in the sixties for sugarcane farmers (Nugent and Gillaspy 1983) and in rural China in the nineties (Ebenstein and Leung 2010). Both find fertility responses but they suffer from serious identification issues and do not claim to nail down a causal effect. ${ }^{6}$

Last, several articles and reports deal with old-age pensions in South Africa (Case and Deaton 1998, Duflo 2003, Jensen 2003, World Bank 2017), but they look at impacts on poverty and inequality, not on fertility. They document that the extension of pensions was a large income shock to the elderly. We come back to this point when discussing the interpretation of our estimates as an insurance effect rather than an income effect. To the best of our knowledge, our article is the first to exploit features of pension systems in Southern Africa to assess the importance of the old-age security motive for childbearing.

\footnotetext{
${ }^{5}$ The sample was small and not representative, the treatment was not randomly allocated and there were large imbalances in female education favoring the treatment group.

${ }^{6}$ In Mexico, pensions were bundled with a family planning program. In China, pensions were introduced in villages with specific features; moreover, the number of children was strictly regulated by population policies.
} 


\section{Context}

This section draws upon Devereux (2001) to describe the main features of the Namibian social pension system. Before 1990, Namibia was de facto a colony of South Africa and subject to the apartheid regime. Pensions were first introduced in 1949 for white residents only. The eligibility was extended to all residents in 1973, but the system remained highly unequal, both in theory and in practice. In theory, different ethnic groups were entitled to different benefits, depending on whether they were favored or not by the regime. In practice, different regions had different coverages because the administration of the pension system for non-whites was decentralized at the bantustan level. Depending on the corruption and inefficiency of the local authorities, eligible people were more or less likely to receive their pensions. Moreover, delivery systems tended to neglect isolated communities, given the logistical problems arising from the provision of payments to unbanked people in sparsely populated areas. Everything changed in the nineties after the end of apartheid and the independence of Namibia. In 1992, inequalities were removed in theory: the Pension Act states that all Namibian residents above age 60 are entitled to the same social pension. A universal, non-contributory system is created. In practice, inequalities persisted until 1996, when the government decided to outsource the pension delivery system to a private company, with the stated goal of reaching universal coverage. This was achieved within a couple of years thanks to two innovations: mobile payment in cash improved access, and biometric identification reduced corruption. In concrete terms, escorted vehicles with cash dispensing machines monthly visit a dense network of payment points. Pensioners wait in line and receive money if their fingerprints match the ones in the computerized database.

Table 1 provides more details about the variation in official benefits across different ethnic groups. Before the Pension Act, Owambo, Kavango and Caprivi were entitled to the lowest amount: 55 rands, which corresponds to the poverty line, 2 dollars per day, or $18 \%$ of the average income. Herero and Nama received roughly $20 \%$ more (65 rands), and Damara $40 \%$ more (75 rands). At the top, Whites were entitled to 382 rands. In 1992, when the Pension Act was adopted, the amount was raised to 120 rands for the bottom four categories, reducing the ratio of highest to lowest from 7:1 to $3: 1$. Two years later, the rate was truly equalized to 135 rands for all, meaning that it decreased substantially for Whites. The final amount was set in 1996 at 160 rands, 3 times the poverty line, or 50\% of the average income, a generous amount by any standards (Devereux 2001). In our data, we can only distinguish four categories: we observe Damara; Herero - Nama; Owambo - Kavengo - Caprivi; and non-Black (an aggregation of White, Coloured and Baster). Tswana, who account for less 
than $0.5 \%$ of the population, are not present.

Turning to the variation in coverage, Table 2 shows the fraction of eligible people who actually received a pension in each of the 13 regions of Namibia in 1993-94, after the Pension Act but before the outsourcing of delivery. The national average was one half, and there is a large variation between regions in the North, just above 30\%, and in the South, just below $80 \%$. In 1998, two years after the outscourcing, the national coverage jumped to $88 \%$ and became very quickly universal. The ILO Social Assistance Database reports that $95 \%$ of eligible individuals received their pensions in 2001. The initial coverage is therefore an excellent predictor of the change in coverage. ${ }^{7}$ One important thing to have in mind is that the initial situation in a region partly reflects the fraction of Whites living there (see maps in Appendix, Figure A.4). During the apartheid, the pension system for Whites was administered at the national level and funded by individual taxation; the vast majority of eligible White people therefore claimed and obtained their pensions (Morgan 1991). Assuming universal coverage for Whites, and based on the average regional coverage and the fraction of Whites among eligible people, we create a measure of initial coverage for non-Whites. The picture remains unchanged in Northern regions, where the fraction of White residents is very low. But in South and Central regions, the high coverage on average masks a lower coverage for Blacks. In particular in Khomas, the region of the capital city Windhoek where most Whites live, discrimination is extreme: only $15 \%$ of eligible Black people have access to pensions.

To sum up, there is some initial variation in amount at the ethnicity level and some variation in coverage at the regional level. Two groups appear as outliers: Whites at the top, and Khomas at the bottom. As discussed in the next sections, both turn out to be very specific in terms of covariates and trends, so we exclude them from the analysis. For Black people living in the provinces, there is a substantial initial variation, between groups well included and groups totally marginalized: coverage varies from $31 \%$ to $65 \%$ across 12 regions, and annual benefits vary from 660 to 900 rands across three categories of ethnic groups. To combine both sources of initial variation, we construct a variable called expected pension. We assume that people form myopic expectations about their future pensions based on what they observe. The current fraction of recipients in the environment is a good proxy for the probability of getting a pension, and the current amount received by pensioners a good proxy for future benefits. These quantities are public information: the distribution of cash is a noticeable event, and pensions are an important source of income for most

\footnotetext{
${ }^{7}$ Figure A.3 in Appendix plots, for each region, the coverage in 1993-94 on the $\mathrm{x}$-axis and the change in coverage between 1993-94 and 2003 on the y-axis. Most regions are very close to the line $y=100 \%-x$ meaning that universal coverage was reached almost everywhere.
} 
households, where grand-parents, parents and children live together (Devereux 2001). Our expected pension variable is equal to the effective coverage times the official annual amount. Before the extension, it varies from 200 to 585 rands across 35 clusters. ${ }^{8}$ After the extension, everybody ends up at the same point, with an expected annual pension close to 2,000 rands (quasi-universal coverage and equalized rate of 160 per month).

The extension of social pensions was a far-reaching reform, but obviously not the only event since the independence of Namibia in 1990. There were major changes (i) in the area of politics, with a new dominant ethnic group, the Owambos; (ii) in the area of economics, with a strong growth during the 2000s; and (iii) in the area of health, with the outbreak of AIDS during the 1990s. Other reforms were supposed to take place - land redistribution, compulsory primary schooling, decentralization of health system, and women's rights - but they were never really implemented. Other social grants were introduced for disabled people or war veterans, but their scope is much more limited than the old-age pensions. ${ }^{9}$ The question is whether these other events were somehow related to both pensions and fertility. In our analysis, we are able to account for potential confounders, like changes in the net cost of children, in the opportunity cost of childbearing, in the returns to quality and in reproductive health. We show that, on these other dimensions, the gap between groups previously excluded from the pension system and groups previously included is not bridged, and even tends to widen. So these confounders cannot explain any catch-up in terms of fertility.

\section{Data}

\subsection{Datasets}

We use two datasets: the Demographic and Health Survey (DHS) and the Namibian Household, Income and Expenditure Survey (NHIES).

The DHS are ideal to compute fertility measures. These are nationally representative household surveys, with waves in 1992, 2000, 2007 and 2013. They record the exhaustive birth history of women aged 15 to 49 (up to 64 in the 2013 wave). The main limitation is that regions are defined in only four categories instead of 13 in the first wave, 1992. This implies that we do not have data at a fine regional*ethnicity level for cohorts born before

\footnotetext{
${ }^{8}$ We have 12 regions and 3 categories of ethnic groups, and one ethnic group does not live in one region.

${ }^{9}$ Old-age pensions account for $87 \%$ of the total budget dedicated to social grants (Subbarao 1998).
} 
1950 and for years before 2000, apart from retrospective information. We use birth histories collected in 2000, 2007 and 2013, to reconstruct birth rates in previous years.

We complement the DHS with NHIES to get information on potential confounders, like wealth, consumption, financial inclusion, access to health, cost of children or urbanization. There are also four cross-sectional waves in 1993-94, 2003-04, 2009-10 and 2015-16. Regions and ethnic groups have a narrow definition, making it possible to aggregate data at the same regional*ethnicity level as in DHS. ${ }^{10}$ We also collected additional data on HIV prevalence at the regional level from the 1994 National HIV prevalence survey conducted by the Ministry of Health and Social Security.

\subsection{Descriptive statistics}

Table 3 provides information about key variables, and some reasons to exclude Whites and the region of the capital city, Khomas, from our sample of interest. The first three columns describe drivers of fertility before the extension of pensions, separating regions with high initial coverage, regions with low initial coverage, and Khomas. Any indicator of development (e.g. poverty, education, urbanization) is worse in low coverage regions. This is partly because very few White people live there: they account for only $3 \%$ of the population, compared to $21 \%$ and $27 \%$ in high coverage regions and in Khomas, respectively. When we exclude White people, in the last three columns, high and low coverage regions become more similar, but Khomas remains different: less poor, more educated, more urban. If we kept Whites and Khomas in the sample, the correlation between initial pension coverage and fertility would therefore capture, to a large extent, differences in socio-economic development. To limit the scope of imbalances, we restrict our sample to Blacks living outside the capital city in the rest of the analysis.

Following the demography literature, we analyse fertility from two different perspectives. First, a period analysis (tempo): the outcome variable is the fertility rate, a measure of the flow of births, and the time variable is calendar year. Second, a cohort analysis (quantum):

\footnotetext{
${ }^{10}$ In theory, it should have been possible to construct the initial pension coverage at a more disaggregated level, for instance separating urban and rural areas, to have more variation and more clusters. NHIES collected individual data on pension receipt in 1993-94, and this information was used by Subbarao (1998) to come up with the estimates in Table 2. But the income module of the questionnaire was lost. We thank Alwis Weerasinghe, who contributed to the computations in Subbarao (1998) for his help in searching for both the physical and digital versions of the questionnaires. It turns out that individual data on pension receipt can only be found for the wave 2015-16, which is not very useful because at that point, there is no variation anymore. Our identification strategy therefore relies on the only piece information that remains the initial coverage by region - combined with variations in official amounts.
} 
the outcome variable is completed fertility, a measure of the stock of births, and the time variable is woman's year of birth. Figure 1 provides descriptive statistics for these variables on our sample of interest, comparing the evolution of fertility between regions with low initial pension coverage (North) and regions with high initial pension coverage (Northeast and South).

The graph on the top left plots the total fertility rate, which is a synthetic measure of how many births a woman would have if she was subject to current age-specific fertility rates at all ages throughout her reproductive life. Before the extension of pensions, in 1992, there was a large gap: just above six children in regions with a low coverage compared to just below five children in regions with a high coverage. After the extension, fertility decreased everywhere, and especially in regions that used to lag behind. The gap was reduced to 0.3 child in 2000 and has completely disappeared since 2006.

In the graph on the top right, we zoom in on the period 1992-2000 and look at age-specific fertility rates over five-year periods. Before the extension, fertility rates were higher in low coverage regions, except at a young age. The gap was the largest between ages 35 and 45: in high coverage regions, fertility rates steadily declined after age 35, whereas in low coverage regions, they remained as high as between ages 25 and 30. Women had more children in low coverage regions because they stopped later, not because they started earlier. After the extension, the situation changed. Fertility decreased across the board, and more in the low coverage regions for women between ages 30 and 45. The age profiles became much more similar between the two groups. The catch-up in total fertility rates is therefore driven by women between 30 and 45 years old in the mid-nineties. This suggests that cohorts born between 1950 and 1965 are the most exposed to the extension.

We reach the same conclusion when we look at completed fertility. The graph on the bottom plots the evolution of total number of children for women above age 45 . For cohorts 1945-50, we observe a one-child gap between low and high pension coverage regions. This gap gradually shrinks and dies out after 1960-65. For youngest cohorts, there is no difference anymore. In the end, the raw data analysis gives us a first hint that those groups who were marginalized in the old pension system initially had a much higher fertility, and rapidly caught up after the extension. 


\section{Empirical Strategy}

To go one step further, this section formalizes the empirical strategy and provides support for the identification assumptions.

\subsection{A fuzzy difference-in-differences in reverse}

We implement a difference-in-differences (DD) but our design has two twists that have implications for the interpretation of our estimates.

First, our DD is in reverse (Kim and Lee 2018). In a standard DD, the control group is never treated, and the treatment group switches from untreated in the pre period to treated in the post period. As is well-known, the coefficient on the interaction term identifies the impact of the treatment on switchers in the post period. The identification assumption is that both groups would have had the same trend in absence of treatment, and researchers commonly provide support for this assumption by testing if pre-trends are parallel. In a DD in reverse, the control group is always treated. In that case, the coefficient on the interaction term identifies the impact of the absence of treatment for switchers in the pre period. ${ }^{11}$ The key assumption is that both groups would have had the same trend in presence of treatment. To test that, we have to look at post-trends.

The second difficulty is that our DD is fuzzy (de Chaisemartin and D'Haultfoeuille 2018). In a sharp diff-in-diff, the fraction of treated moves from 0 to 1 in treatment group and remains 0 in control group. Apart from the parallel trend, no assumption on homogenous treatment effect is required, because there is only one population treated at one point in time: the treatment group in the post period. Whereas in a fuzzy diff-in-diff, some people in both groups and both periods are treated, and what we exploit is the fact that the fraction of treated increases more in treatment than in control. In that case, we have to assume that the treatment effect is stable in time and homogenous between groups. This implies that we cannot have groups that are too different from each other, in terms of characteristics that could influence the impact of pension on fertility. ${ }^{12}$

We argue that identification assumptions are likely to hold for our sample of interest, Blacks living outside the capital city. First, the fact that high and low initial coverage

\footnotetext{
${ }^{11}$ We can always redefine the treatment as the absence of treatment, e.g. need for old-age support. However, this does not solve the fundamental issue that treatment and control are different in the pre period, and similar in the post period, contrary to a standard DD setting.

${ }^{12}$ de Chaisemartin and D'Haultfoeuille (2018) propose estimators that do not rely on the assumption of homogenous treatment effects. Unfortunately, we cannot implement them because we are unable to separate, within groups, treated and untreated individuals.
} 
regions have the same fertility once everybody gets a pension is reassuring (cf. Figure 1). Second, Table 3 shows that, provided that we exclude Whites and Khomas, high and low coverage regions were similar on many dimensions before the extension: poverty, education, access to health, child labor. The main difference is the fraction of urban households, and we discuss extensively the implications of this difference in the Results section. Third, Table 4 provides evidence in favor of parallel trends. We estimate the linear annual trend in birth rate, before, during and after the extension. We find a flat trend before and after, and a sharp decline during the extension. Next, we test if pre-trends and post-trends are correlated with the initial pension variable that we use in the econometric analysis. They are not: coefficients on the interaction terms Before $\times$ InitialPension and After $\times$ InitialPension are not significant and very close to zero. Trends were different only during the extension, between 1992 and 1997: fertility declined less in groups that had initially higher pensions, i.e. groups that were less affected by the reform. ${ }^{13}$ Another way to look at pre-trends is using retrospective information in the 1992 wave to estimate total fertility rates in 1987. Figure A.5 in Appendix shows that the catch-up between high and low coverage regions had not started before the extension: lines are parallel between 1987 and 1992.

\subsection{Period specification}

The period specification is at the mother*year level and writes as follows:

$$
\begin{aligned}
\text { Birth }_{i, t}= & \alpha \text { InitialPension }_{c(i)}+\beta \text { Post }_{t}+\gamma \text { InitialPension }_{c(i)} \times \text { Post }_{t} \\
& +\nu Z_{i}+\eta X_{c(i), p r e}+\delta X_{c(i), p r e} \times \text { Post }_{t}+\mu_{w(i)}+\epsilon_{i, t}
\end{aligned}
$$

The outcome variable is $B i r t h_{i, t}$, a dummy equal to 1 if woman $i$ surveyed in cluster $c$ in wave $w$ gave birth in year $t$. Each wave provides information on the birth history of women aged 15 to 49 at the time of the survey. If we want to use retrospective data to compute comparable birth rates in the past, we need to pay attention to the age structure of the sample. For instance, the 2000 wave gives information about the probability to give birth in 1999 for women aged 14 to 48 at that time, in 1998 for women aged 13 to 47 etc. To keep the age structure constant over a given period of time, there is a tradeoff between going far back and retaining older ages in the sample. We chose to restrict the analysis to the last 10

\footnotetext{
${ }^{13}$ Looking at trends provides another reason to exclude the White ethnic group and the Khomas region from the sample. Table A.1 in Appendix shows that, in column (1), Whites have different pre-trends - the decline in fertility started earlier; and in column (2), Blacks in Khomas region have different pre-trends and post-trends - fertility declined throughout the whole period.
} 
years before wave $w$. Thus we are able to construct birth rates for women aged 15 to 40 in every year between 1990 and 2012 .

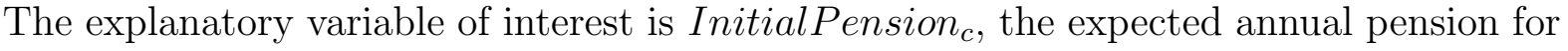
cluster $c$ before the extension. As explained in the Context section, InitialPension varies between 0.2 and 0.585 thousand rands across 35 clusters (=ethnicity*region). In the main

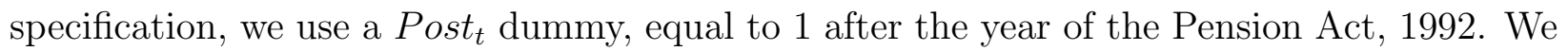
then allow the coefficient $\gamma_{t}$ to vary year-by-year to look at the time profile.

In some specifications we include controls, either time-invariant individual controls $Z_{i}$, or cluster-level controls measured before the extension $X_{c(i), p r e}$, and interacted with the Post variable. We also have a survey wave fixed effect. Last, we use survey weights and we cluster standard errors at the level of the treatment, i.e. ethnicity* region. ${ }^{14}$

\subsection{Cohort specification}

The cohort specification has a similar structure, except for being at the mother level. We look at completed fertility for different cohorts, instead of birth rates for different years:

$$
\begin{aligned}
\text { NbBirth }_{i}= & \alpha \text { InitialPension }_{c(i)}+\beta \text { Exposure }_{k(i)}+\gamma \text { InitialPension }_{c(i)} \times \text { Exposure }_{k(i)} \\
& +\nu Z_{i}+\eta X_{c(i), p r e}+\delta X_{c(i), p r e} \times \text { Exposure }_{k(i)}+\epsilon_{i}
\end{aligned}
$$

The outcome variable is $N b B i r t h_{i}$, the number of children born to woman $i$ in cluster $c$ and cohort $k$. We keep only women aged 44 to 50 in wave $w$. We chose this specific age range to be able to put waves next to each other and have observations for each cohort between 1950 and 1969.

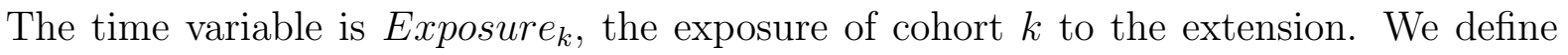
the exposure in three ways: not exposed vs. fully exposed, partially exposed or cohort-bycohort. ${ }^{15}$ Figure 2 explains the construction of the exposure variable. The graph shows the theoretical exposure of different cohorts to the extended pension system. The old cohorts are not exposed, because they already had all the children during the old system. The young cohorts are fully exposed, because they started having children in the new system. The cohorts in between are partially exposed because they already had some children, but not

\footnotetext{
${ }^{14}$ Alternatively, we can collapse the data at the cluster*year*wave level. This sample has 909 observations (35 clusters and 23 years, some of them exist in two DHS waves). We also tried two-way clustering at the ethnicity*region level and at the woman level. In both cases, we get results with the same significance levels as our main specification (tables available upon request).

${ }^{15}$ Our setting is similar to Bleakley (2010), who uses eradication campaigns to study the impact of malaria in childhood on economic outcomes. We draw upon his article to design the cohort specification.
} 
all of them. The precise shape builds upon (i) the descriptive statistics, showing a strong response in the late reproductive period, and (ii) some data constraints, requiring enough observations not exposed and fully exposed. We assume a linear exposure for cohorts born between 1955 and 1965. In the Pre-Post specification, we compare cohorts born before 1955 and cohorts born after 1965. In the Partial specification, we keep all cohorts and define Exposure $_{k}=\max (\min (10 ; k-1955) ; 0) / 10$. In the Cohort-by-cohort specification, we do

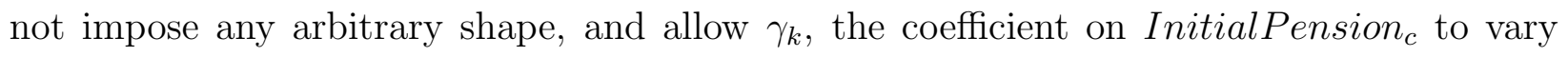
flexibly.

\section{Results}

\subsection{Period analysis}

Table 5 displays the estimates of the period specification. In the first column, we include no control. Before the extension, there was a negative correlation between initial pensions and birth rates. After the extension, the correlation completely disappears: we get a p-value of 0.92 when summing the coefficients on Initial Pension and Post $*$ Initial Pension. As explained above, the coefficient on the interaction term identifies the impact of the absence of pensions in the pre-period: an increase by 9 percentage points in the annual probability of birth.

In the next columns, we add controls block by block. The difference-in-differences coefficient increases and becomes more significant when we control for indicators of urbanization and wealth in columns 2 and 3. This is because groups more or less excluded from the old pension system have diverged on these dimensions, as shown by Figure A.6 in Appendix. In 1993-94, regions with a high pension coverage were as poor as the others, although they were less rural. The large fraction of urban poor is typical of townships built under the apartheid regime. Township residents had a better access to pensions, especially because they were more likely to have a bank account. But their economic opportunities were limited by a series of rules designed to ensure the availability of cheap labor in cities. These places benefited relatively more from the end of the apartheid and became gradually much less rural and poor than the rest of the country. As a result, the gap between high and low initial pension regions widened over time. Since urbanization and wealth are strong drivers of low fertility, these confounding dynamics create an attenuation bias in the baseline specification. When we additionally control for access to health services, cost of children, AIDS, child mortality and maternal education, the difference-in-differences coefficient remains stable, around 15-17 
percentage points.

In terms of magnitude, the coefficient on the interaction term is between 9 and 17 percentage points yearly, depending on whether we include controls or not. This corresponds to 2.25 to 4.25 children over 25 years of reproductive life. Given the support of the pension variable, from 0.2 to 0.585 , this implies a difference of 0.9 to 1.6 children between groups with minimal and maximal initial pensions. As a point of comparison, consider for example that the initial difference between rural and urban areas was 2.3 children; it was 2 between low and high educated women and 3.3 between the first and the fifth wealth quintiles. Pensions hence explain variations that are lower, but not so much lower, than the most obvious drivers of fertility.

We then look at heterogeneity by age to see if the hint from the descriptive statistics is validated. Figure 3 shows that the interaction term is positive and significant only for women above age 25. Interestingly for those women, adding controls makes little difference. The stability of the estimates supports the assumption that older women are not affected by confounding factors. In contrast, younger women seem to be affected by the divergence in wealth and urbanization happening at the same time as the extension of pensions. For them, the difference-in-differences coefficient is slightly negative in the absence of controls and becomes null when we add controls. This means that fertility in early reproductive years decreased more in regions with higher initial pension coverage, because these regions experienced a faster structural transformation. This suggests that urbanization and wealth impact the onset of fertility in the opposite direction as the effect of pensions that we try to highlight.

To know more about the timing of the catch-up, we run the regression year-by-year and plot the coefficient on initial pension in Figure 4. The correlation between initial pensions and fertility was significantly negative before the Pension Act. It gradually disappears during the extension, between 1993 and 1998, and remains stable around zero afterwards. These patterns confirm that the catch-up precisely coincides with the extension, providing thus support for the identification assumptions.

\subsection{Cohort analysis}

Table 6 displays the estimates of the cohort specification: the pre-post analysis is shown in Panel A and the partial analysis exploiting all cohorts is shown in Panel B. Both lead to the same conclusion. There is a negative correlation between initial pension and completed fertility for older cohorts, who were not exposed to the extension. This correlation disappears 
for younger cohorts, who were exposed: the sum of the coefficients on Initial Pension and Exposure * Initial Pension is never significantly different from zero. Again, the differencein-differences coefficient is higher and more precisely estimated when we control for the confounders.

Coefficients range between 2.7 and 5.7 children, depending on the specification. They imply a difference of 1 to 2.2 children between groups with minimal and maximal initial pensions. Compared to the period specification, estimates are larger because they take into account adjustments made after age 40. However, the cohort analysis gives noisier estimates due to the smaller sample size.

When we do not impose any functional form on the exposure variable and plot the coefficient on initial pension cohort-by-cohort, we get the graph in Figure 5. The pattern is for the most part similar to the theoretical graph, namely a negative correlation followed by a progressive catch-up and then a plateau. The only difference is that we expected a slower pace, until the mid-60s, while the actual catch-up happened in less than 10 years between cohorts 1954-55 and cohorts 1960-61. The catch-up was therefore partial for women in their late thirties during extension, and complete for women in their early thirties. This is consistent with a recent result by Chatterjee and Vogl (2018), who argue that only economic fluctuations occurring after the age of 30 influence completed fertility in developing countries. What happens earlier is compensated later in life.

\subsection{Robustness}

We conduct several robustness tests, varying the sample and the model specification. Results are reported in Tables A.2 and A.3 in Appendix. They remain stable when we (i) control for cluster and year or cohort fixed effects; (ii) use a binary treatment; (iii) exploit only the regional variation in coverage, and not the ethnic variation in amount; (iv) allow for Owambospecific levels and trends; and (v) restrict to Northern regions. Moreover, we excluded one region at a time to make sure that our results are not driven by a specific area. Coefficients on the interaction term range from 9 p.p. to 25 p.p. in the period specification, and from 3.5 to 7.5 children in the cohort specification. They are always significant at conventional levels.

One particular worry is migration. Many people moved during the 1990s, once restrictions put in place during the apartheid were lifted. In our sample, $28 \%$ of women surveyed in 2000 had migrated over the past 10 years. This could jeopardize the interpretation of our estimates as causal effects in case of differential migration within or between regions. Within regions, 
rural to urban movements play against us because the fraction of rural households started lower and decreased faster in regions with higher initial pension coverage (cf. Figure A.6 in Appendix). All else equal, rural-to-urban migration would therefore predict a divergence in fertility. Between regions, migration could potentially explain the catch-up observed in Figure 1 in two situations. First, if people with low fertility moved to low coverage regions, while people with high fertility moved to high coverage regions, this would generate a convergence. This is not the case in the data: migrants and natives have the same fertility. ${ }^{16}$ Coherently, we still observe a catch-up when we exclude those who migrated in the 10 years preceding the survey, as shown by in Figure A.7 in Appendix. The second situation is outof-the-sample migration. If people with many children migrated away from low coverage regions to other countries or to the capital city, we would not observe them in 2000. This could rationalize the descriptive statistics, but not the econometric results, which are based on retrospective data. In the regressions, we observe a woman in wave 2000 and look at her birth history. The correlation between pension and fertility before 1992 is estimated on women who are, by construction, in the sample in 2000. When we exclude the migrants from the regressions, the difference-in-differences coefficients remain the same in magnitude but are imprecisely estimated since we lose many observations. All in all, the catch-up is not the result of population movements.

To further rule out composition effects, we consider an alternative specification for the period analysis which includes mother fixed effects. The baseline specification looks at the evolution of the birth rate of different women, keeping the age structure constant. A specification with mother fixed effects looks at the birth rate of the same woman, at different ages. This reduces power because only women older than 15 in 1992 contribute to identification;

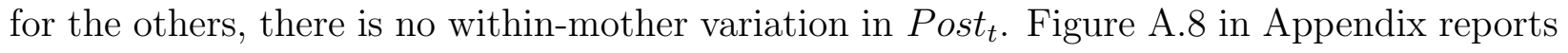
the difference-in-differences coefficient, without and with controls, for different sub-samples. They are always positive, but only significant at $5 \%$ when we focus on women older than 25 in 1992. The older the sample of mothers, the higher the coefficient and also the higher the standard errors since we have fewer observations. All this is consistent with our results without mother fixed effects.

\footnotetext{
${ }^{16} 6.17$ children for migrants compared to 6.36 for natives in low coverage regions (p-value of the difference $=0.79$ ) and 5.78 children for migrants compared to 5.79 for natives in high coverage regions ( $\mathrm{p}$-value of the difference $=0.99)$.
} 


\subsection{Mechanisms}

So far, all results point to the following conclusion: in presence of pensions, women have fewer kids during the late reproductive life. The relevant margin seems to be stopping rather than starting or spacing. Figure 6 provides evidence supporting this idea.

The graphs on the top show a strong convergence in self-reported fertility preferences between 1992 and 2000. ${ }^{17}$ In regions with low initial pensions before the extension, the average ideal number of births was higher, and the fraction of women who wanted to stop having children was lower. This is no longer true after the extension. Both types of regions show very similar numbers during the post-period 2000-2013. These patterns support our interpretation of a change in desired fertility, and are inconsistent with stories emphasizing changes in ability to control births.

The graphs on the bottom plot the evolution of age at last birth and age at first birth. Contrary to self-reported preferences that can change from one day to the next, the average ages at last and first birth display some inertia. There is a stock of women for whom these ages are already determined and do not vary across waves. We therefore expect a more progressive convergence. This is what we find for age at last birth: between 1992 and 2013, it gradually decreases in low coverage regions down to the level observed in high coverage regions, where it remained stable throughout the period. For age at first birth, we observe a different pattern. There is also a convergence, but the starting points are reverse: the age at first birth is higher in low coverage regions, meaning that women start having children later. Over time, the age is slightly decreasing, whereas in high coverage areas, there is a slight increase. This rules out the possibility that the decrease in total fertility in low coverage regions is driven by factors influencing the onset of births, like changes in female schooling or in marriage practices. The patterns in age at first birth are in line with our previous results on younger women suggesting that the onset of fertility was affected by confounding factors that go in the opposite direction.

All in all, the negative impact of social pensions on fertility operates through a reduction in how many children women want to have. This is the main take-away in terms of policy, although this is not enough to totally nail down the old-age security motive. Besides the insurance mechanism, pensions can indeed influence fertility in two ways: through female labor supply and household income. Case and Deaton (1998) find that the extension of social pensions in South Africa had a substantial effect on household welfare, not only for

\footnotetext{
${ }^{17}$ We can only look at preferences reported by women, because these questions were not asked to men in 1992.
} 
the elderly but also for other family members. One reason is that many families live with a pensioner and directly benefit from the transfer. Moreover, pensioners may have more time and resources to devote to their grand-children, which can potentially prompt women into working outside their homes, or even temporarily migrate for work. ${ }^{18}$

The female labor supply channel is unlikely to explain our results for two reasons. First, Jensen (2003) shows that, in the similar South African context, old-age pensions had no effect on labor supply, migration, or co-residence. Comparing men and women, above and below the age eligibility threshold, before and after the extension, he finds that the proportion of migrants, the earnings of members who live permanently in the household as well as the earnings of temporary migrants, and the number of members, are the same for households with and without old-age pension recipients. Second, in our sample, there is no catch-up in female labor force participation between high and low initial coverage regions. As shown by the left graph in Figure A.9 in Appendix, the gap has even widened between 1992 and 2000.

Turning to the income channel, it is unclear in which direction a rise in household earnings would influence fertility. On the one hand, the macro literature tends to model children as normal goods and provides evidence from various settings that fertility is pro-cyclical (Chatterjee and Vogl 2018). This would predict a positive impact of pensions on fertility. On the other hand, the experimental literature on cash transfers has produced mixed results: positive, negative and insignificant impacts on fertility have been found (see Khan, Hazra, Kant, and Ali (2016) for a survey). The only consensus seems to be that unconditional transfers to young women delay first births. There is no evidence that cash transfers reduce completed fertility among older women, so the income effect alone fails to account for our results. ${ }^{19}$ In addition, we can try to isolate the old-age security motive by restricting the analysis to households where no one is eligible for pensions. In our sample, roughly $30 \%$ of women live with a person older than 60 years old. Table A.4 in Appendix estimates the period specification, without and with controls, for households living or not with an elderly. The difference-in-differences coefficient is positive and significant in the absence of an elderly, and larger than in the whole sample. When an elderly lives in the household, the coefficient is also positive, but smaller in magnitude. This suggests that the old-age security motive is

\footnotetext{
${ }^{18} \mathrm{~A}$ contributory pension system could also raise female labor force participation by making employment more attractive. But the Namibian system is non-contributory.

${ }^{19}$ It is sometimes argued that cash transfers can reduce unwanted births by making modern contraceptives more affordable. This is not the case in our sample. The right graph in Figure A.9 in Appendix shows that the fractions of unwanted and unplanned births were the same in high and low coverage regions in 1992, so they fail to account for the initial differences in realized fertility. And they tend to increase over time especially in low coverage regions, which is inconsistent with the idea of an improved control.
} 
partly offset by an income effect that raises fertility.

\section{Discussion}

Which lessons can be learnt from the Namibian experience? We argue that our estimates shed light on the impact of potential extensions of social pension systems on fertility decline in Sub-Saharan Africa. As shown by Figure A.2 in Appendix, five countries currently have undeveloped systems: Mozambique, Nigeria, Uganda, Tanzania and Kenya. The characteristics of these systems are roughly similar to the worst initial situation in Namibia: the coverage is below $25 \%$ and the benefits are between 10 and $15 \%$ of average income. Fertility levels are also about the same as in the lowest initial pension areas, at five to seven children per woman, and they share the same pro-natalist culture. Therefore, we can use our Namibian estimates to try to predict what would happen to these countries if they implemented a pension system similar to the best initial situation in Namibia, namely a coverage of $2 / 3$ and benefits around $25 \%$ of the average income. This is a relevant target because it would mimic developed pension systems currently operated in Africa (e.g. in South Africa). The most conservative estimate is given by the period specification without any control: it predicts a reduction in completed fertility by one child. But the cohort analysis and the discussion about confounders give good reasons to think that the effect is in fact larger, probably around 1.5-2 children. In terms of timing, all specifications point to a rapid adjustment. If the response was concentrated in the early reproductive period, by postponing the age at first birth, we should wait for 20-25 years to observe a decrease in completed fertility. This is not the case: women respond by bringing the age at last birth forward. The decrease is likely to be observed among older cohorts immediately after the extension, and to be completed within a decade.

In the vast majority of Sub-Saharan African countries, there is no social pension system. If we want to use our estimates to predict what would happen after the introduction of a new system, we need to make strong assumptions. We do not observe any group completely excluded from the system in Namibia, so we do not study changes at the extensive margin. Our initial pension variable ranges from 0.2 to 0.6 thousand rands. If we assume no discontinuity at zero and a linear effect, we would predict that the impact of going from no pension to the best initial situation is roughly $50 \%$ larger than the impact of going from the worst to the best initial situation. This implies a reduction by 1.5 to three children, based on the discussion above. Nonetheless, Table A.5 in Appendix provides evidence that the impact of 
pension on fertility is in fact non-linear: it is very strong at low levels of protection, and disappears as protection improves. This suggests that the fertility response to the introduction of a pension system could be different, and potentially larger, compared to the one we identified after the extension of the Namibian system.

All these findings are consistent with a model in which children are the best way to transfer money from one period to the next. For parents, offspring are a source of expenses as children, and a source of earnings as adults. The decreasing marginal utility of consumption predicts that couples have more children if income from other sources in old-age, such as social pensions, is lower. This effect is non-linear; in particular, if the elderly entirely depend on transfers from their children, people are willing to incur large costs as young adults to ensure that their consumption does not fall below subsistence levels later on. Adding the risk that children may "default" on their parents reinforces this effect, by creating an incentive to hoard. Parents want at least one surviving child to be able to consume in oldage. Regarding the timing of births, our patterns are consistent with a cost function that (i) generates incentives to space out births and (ii) makes pregnancies during teenage years more costly than during the thirties.

\section{Conclusion}

This paper provides quasi-experimental support for the old-age security motive for fertility. Exploiting variation in time, regions and ethnic groups in Namibia, we show that social pensions have a large negative impact on fertility: women stop having children at a younger age. This has important policy implications. The majority of Sub-Saharan African governments target a reduction in fertility and have no pension system. Our results suggest that introducing or expanding social pensions could go a long way in fostering fertility decline. Including the fertility dimension in the cost-benefit analysis of pension systems is therefore crucial. On the benefits side, contributing to reach population targets is an argument in favor of social pensions. On the costs side, curbing population growth might affect the sustainability of the system.

Becoming aware of the fertility responses to old-age pensions opens the way for new insights into the efficiency of pension systems. What is the optimal mix of coverage and benefits to reach a given fertility level? Do people give birth to a socially efficient number of

children when a formal system allows them to pool the risks of child "default"? In addition to the number of births and in the same vein as Bau (2019), two related outcomes that cannot 
be analyzed in our setting due to data limitations would be worth investigating. What is the impact of pensions on child quality? ${ }^{20}$ And what is the relationship between social pensions, gender norms related to caregiving, and gender preferences? ${ }^{21}$ Hopefully, recent and future extensions of pension systems in Sub-Saharan Africa will provide suitable empirical designs to study these questions.

\section{References}

Banerjee, A., X. Meng, T. Porzio, and N. Qian (2014): "Aggregate fertility and household savings: A general equilibrium analysis using micro data," NBER Working Paper No. 20050.

Barro, R. J., And G. S. Becker (1989): "Fertility choice in a model of economic growth," Econometrica, 57, 481-501.

Bau, N. (2019): "Can Policy change Culture? Government Pension Plans and Traditional Kinship Practices," Manuscript.

Bleakley, H. (2010): "Malaria eradication in the Americas: A retrospective analysis of childhood exposure," American Economic Journal: Applied Economics, 2(2), 1-45.

Boldrin, M., M. D. NArdi, And L. Jones (2015): "Fertility and Social Security," Journal of Demographic Economics, 81, 261-299.

Boldrin, M. B. M., And L. E. Jones (2002): "Mortality, fertility and saving in malthusian economy," Review of Economic Dynamics, 5, 775-814.

Cai, F., J. Giles, and X. Meng (2006): "How Well Do Children Insure Parents Against Low Retirement Income? An Analysis Using Survey Data from Urban China," Journal of Public Economics, 90(12), 2229-2255.

Caldwell, J. (1978): "A theory of fertility: from high plateau to destabilization," Population and Development Review, 4, 553-577.

— (1982): Theory of Fertility Decline. Academic Pres.

\footnotetext{
${ }^{20}$ In theory, the income effect and the quality-quantity trade-off would predict an increase in parental investments, while changes in incentives to bring up successful children would predict the opposite. We are unable to convincingly test which forces prevail using our period and cohort design, because we do not have retrospective information on child quality, and spillovers between siblings make it difficult to define which cohorts of children are exposed to the extension.

${ }^{21}$ We constructed an indicator of son preference based on differential birth spacing and found preliminary evidence that son preference tends to disappear in presence of pensions. But we lack power to reach a definitive conclusion. Son-preferring fertility behaviors are barely detectable in Namibia, and the presence of matrilineal ethnic groups, although interesting in principle, further reduces the sub-samples of interest in practice.
} 
Case, A., and A. Deaton (1998): "Large Cash Transfers to the Elderly in South Africa," The Economic Journal, 108, 1330-1361.

ChatterJee, S., And T. Vogl (2018): "Escaping Malthus: Economic Growth and Fertility Change in the Developing World," American Economic Review, 108(6), 1440-1467.

Cox, D., And E. Jimenez (1992): "Social Security and Private Transfers in Developing Countries: The Case of Peru," World Bank Economic Review, 6(1), 155-169.

de Chaisemartin, C., and X. D'Haultfoeuille (2018): "Fuzzy Differences-inDifferences," Review of Economic Studies, 85(2), 999-1028.

Devereux, S. (2001): Social Pensions in Namibia and South Africa, vol. 379. Institute of Development Studies.

Duflo, E. (2003): "Grandmothers and Granddaughters: Old-Age Pensions and Intrahousehold Allocation in South Africa," World Bank Economic Review, 17(1), 1-25.

Ebenstein, A., And S. Leung (2010): "Son Preference and Access to Social Insurance: Evidence from China's Rural Pension Program," Population and Development Review, 36(1), 47-70.

Guinnane, T. (2011): "The Historical Fertility Transition: A Guide for Economists," Journal of Economic Literature, 49(3), 589-614.

Hoddinote, J. (1992): "Rotten Kids or Manipulative Parents: Are Children Old Age Security in Western Kenya?," Economic Development and Cultural Change, 40(3), 545565 .

International Labour Organization (2018): "Social protection for older persons: Policy trends and statistics 2017-19.," Social Protection Policy Papers, 17.

JEnsen, R. (2003): "Do private transfers 'displace' the benefits of public transfers? Evidence from South Africa," Journal of Public Economics, 88, 89-112.

JuAREz, L. (2009): "Crowding out of private support to the elderly: Evidence from a demogrant in Mexico," Journal of Public Economics, 93(3-4), 454-463.

Khan, M. E., A. Hazra, A. Kant, and M. Ali (2016): "Conditional and Unconditional Cash Transfers to Improve Use of Contraception in Low and Middle Income Countries: A Systematic Review.," Studies in family planning, 47(4), 371-383.

Kim, K., And M. LeE (2018): "Difference in differences in reverse," Empirical Economics, Accepted/In press, 1-21.

Leibenstein, H. (1957): Economic Backwardness and Economic Growth. Wiley. 
Levine, S., S. VAn Den Berg, and D. Yu (2011): "The impact of cash transfers on household welfare in Namibia," Development Southern Africa, 28(1), 39-59.

Morgan, R. (1991): "State pensions as an income safety net in Namibia," Food policy, pp. 351-359.

Nugent, J. (1985): "The Old-Age Security Motive for Fertility," Population and Development Review, 11(1), 75-97.

Nugent, J., And T. Gillaspy (1983): "Old-age pensions and fertility in rural areas of less developed countries: Some evidence from Mexico," Economic Development and Cultural Change, 31(4), 809-829.

OliveIRA, J. (2016): "The value of children: Inter-generational support, fertility, and human capital," Journal of Development Economics, 120, 1-16.

Piggott, J., And A. Woodland (2016): Handbook of the Economics of Population Aging. Elsevier.

Ridker, R. (1980): "The No-Birth Bonus Scheme: The use of savings accounts for family planning in South India," Population and Development Review, 6(1), 31-46.

Stolnitz, G. (1983): "Three to five main challenges to demographic research," Demography, 20, 415-432.

SubBaraO, K. (1998): "Namibia's social safety net: Issues and options for reform," Policy Research Working Paper 1996, Washington DC : World Bank.

United Nations (2013): "World Population Policies.," United Nations publication, $\mathrm{ST} / \mathrm{ESA} / \mathrm{SER}, \mathrm{A} / 341$.

(2015): "World Population Prospects: The 2015 Revision.," United Nations publication, ESA/P, WP/241.

_ (2017): "World Population Prospects: The 2017 Revision.," United Nations publication, ESA/P, WP/248.

World BAnK (2017): "Does Fiscal Policy Benefit the Poor and Reduce Inequality in Namibia?," IBRD-IDA / The World Bank. (2018): "The State of Social Safety Nets 2018," Washington DC: World Bank. 


\section{Figures and Tables}

Figure 1: Evolution of fertility, by initial pension coverage
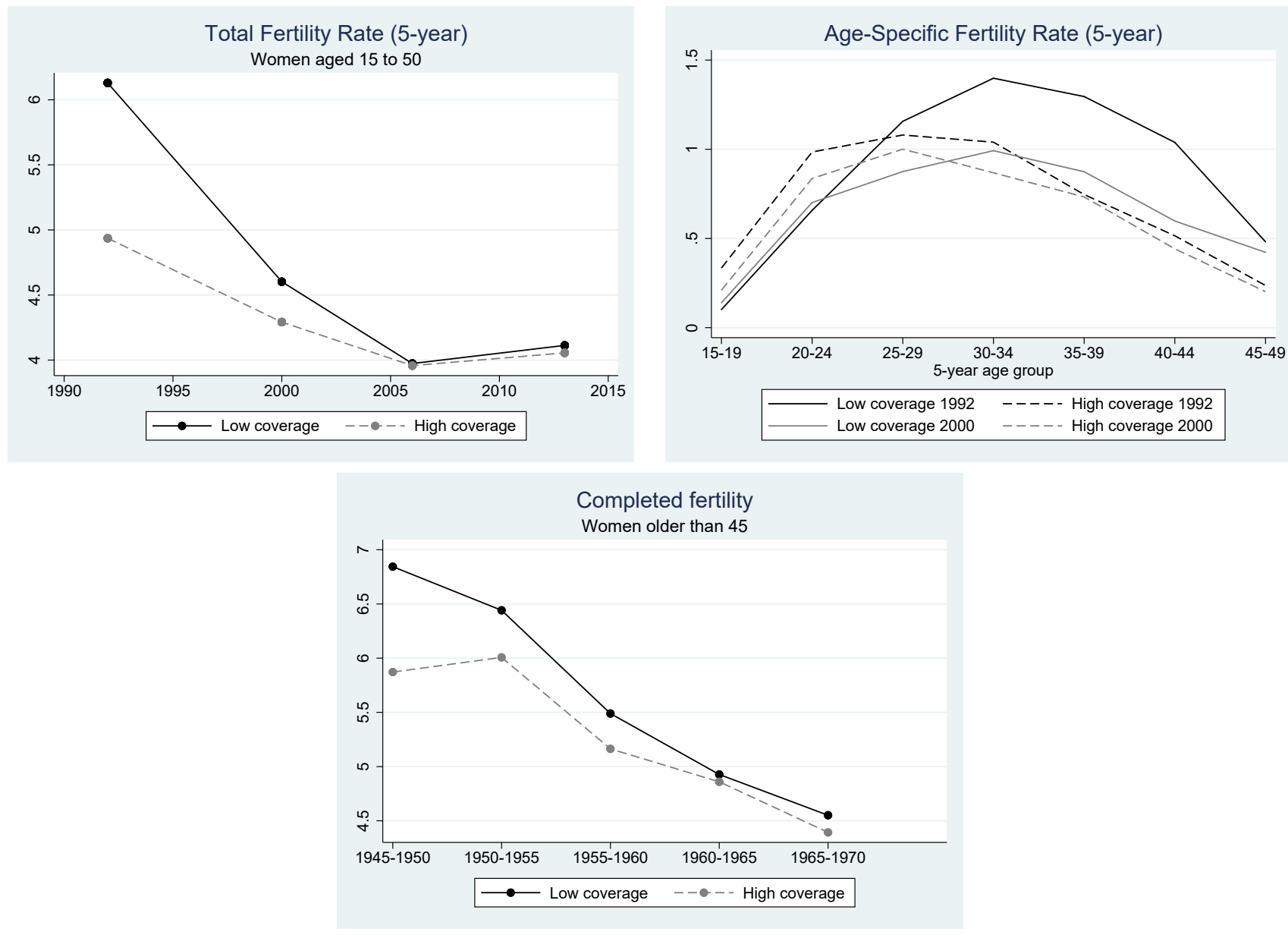

The graphs plot the evolution of several measures of fertility in regions with low (North, solid lines) and high (Northeast and South, dashed lines) initial pension coverage. The extension of pensions took place between 1992 and 1997. Data: DHS. Sample: non-White women aged 15 to 50 in the fertility rates graphs, older than 45 in the completed fertility graph.

The graph on the top left shows Total Fertility Rate, a synthetic rate measuring how many births a woman would have if she was subject to current age-specific fertility rates at all ages throughout her reproductive life. Own computation based on age-specific birth rates in the five years preceding each survey.

The graph on the top right shows Age-Specific Fertility Rates, before the extension (in 1992, black lines) and after the extension (in 2000, grey lines). The Age-Specific Fertility Rate measures how many births an average woman has during five-year periods. Own computation based on age-specific birth rates in the five years preceding each survey.

The graph on the bottom shows completed fertility, by mother's cohort. When the extension of pensions took place during the mid-nineties, women born in 1945 were around age 50 while women born in 1970 were around age 25. Completed fertility is the total number of births born to the average woman. 
Figure 2: Theoretical exposure to extended pensions, by women's cohort

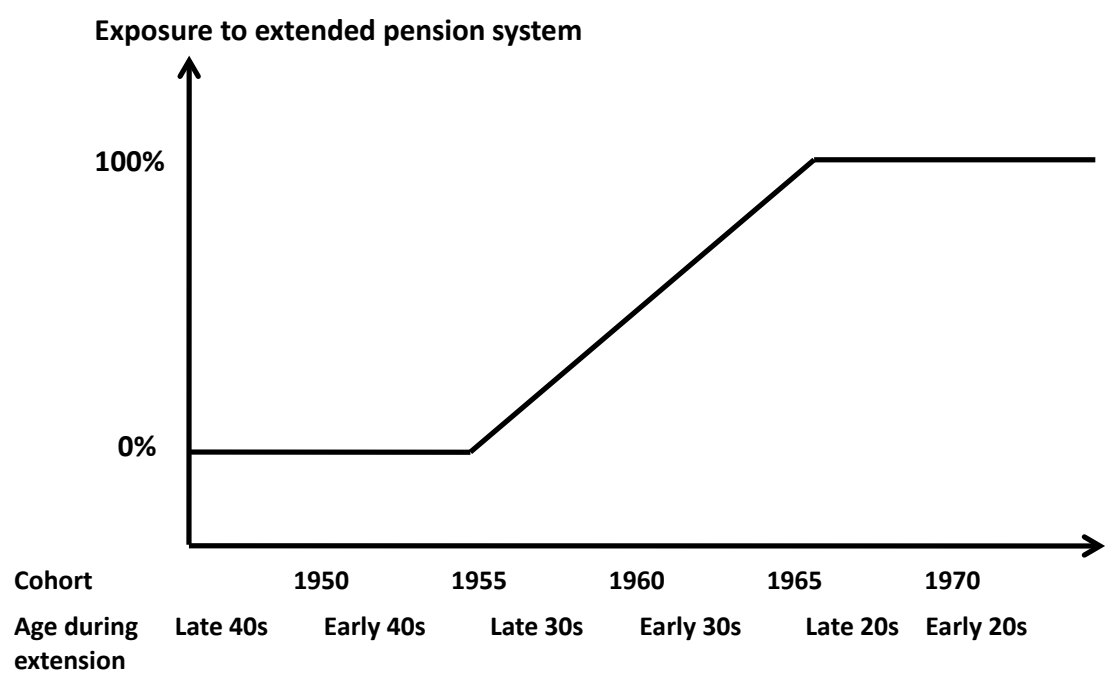

The figure shows the theoretical exposure of different cohorts to the new pension system. Depending on their age in the mid-nineties, they were always exposed, never exposed, or only during a fraction of their reproductive life. The exact formula is: Exposure $_{k}=\max (\min (10 ; k-1955) ; 0) / 10$.

Figure 3: Period analysis - difference-in-differences coefficient, by age group

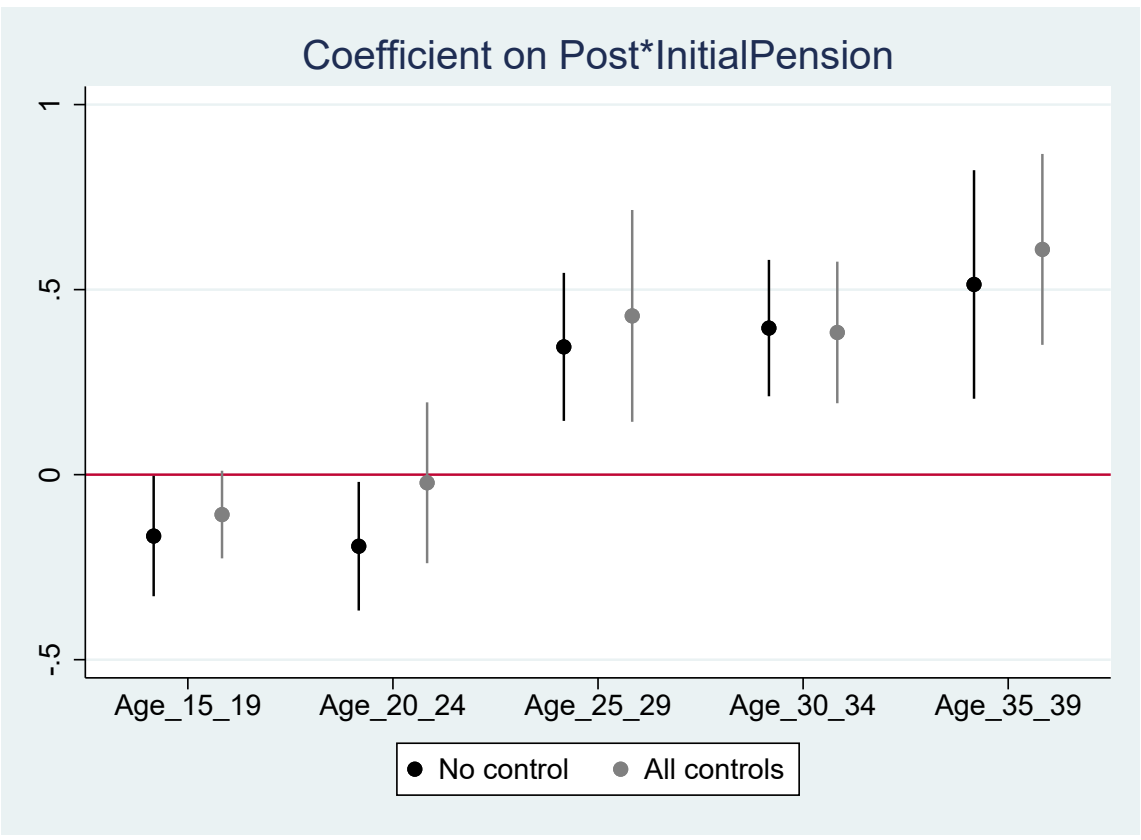

The graph plots $\gamma$, the coefficient on the interaction between InitialPension ${ }_{c}$ and Post $_{t}$ in Equation 1, for different age groups, controlling or not for the full set of controls (urban, wealth, access to services, cost of children, AIDS, U5 mortality, maternal education). The vertical lines represent the confidence intervals at $95 \%$. 
Figure 4: Period analysis - impact of initial pension on probability of birth, by year

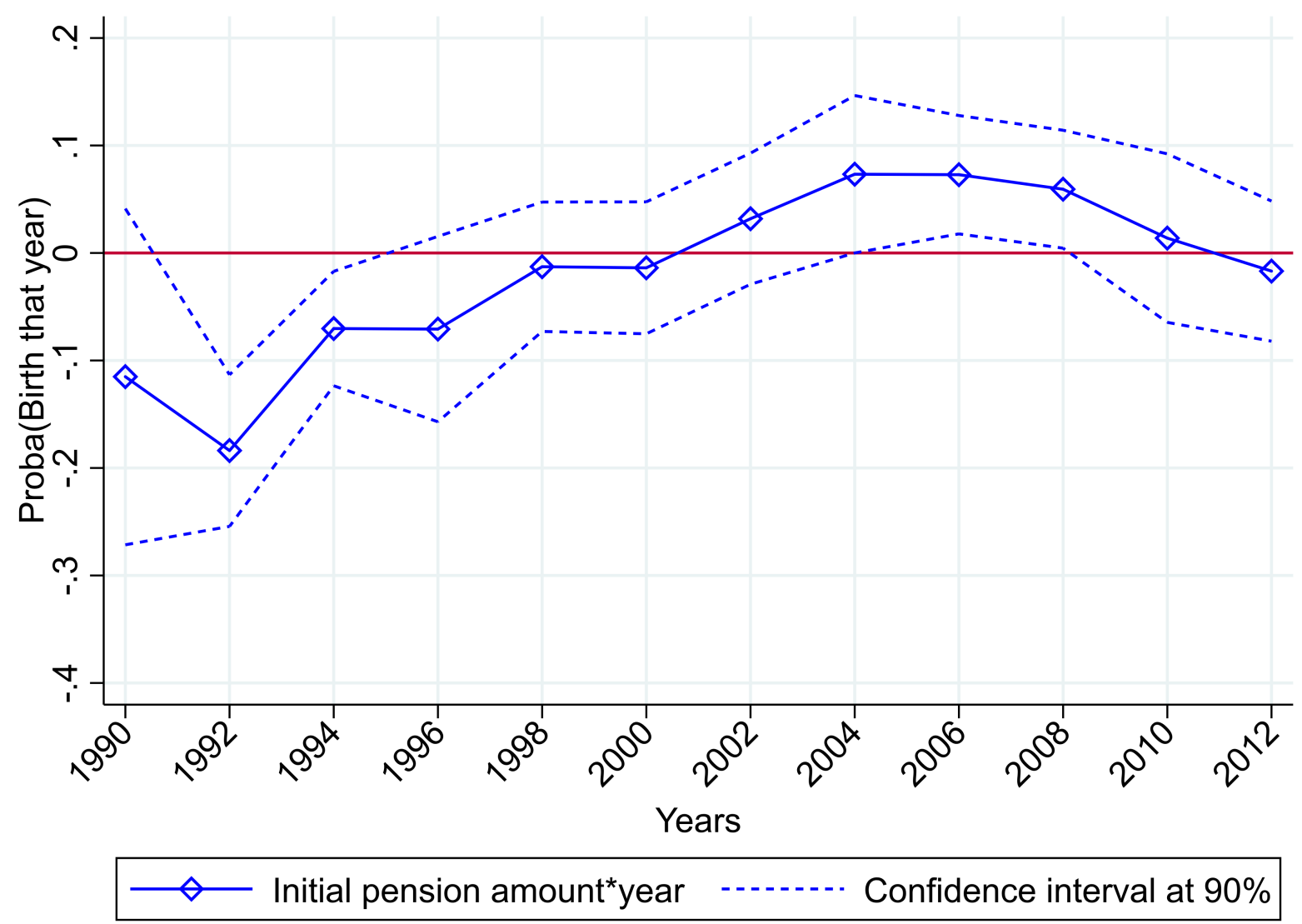

The graph plots $\gamma_{t}$, the coefficient on the interaction between InitialPension $_{c}$ and an indicator for year $t$ or $t-1$, in the period specification controlling for the full set of controls (urban, wealth, access to services, cost of children, AIDS, U5 mortality, maternal education). We pool together years $t$ and $t-1$ to increase precision. 
Figure 5: Cohort analysis - impact of initial pension on completed fertility, by cohort

(a) Without controls

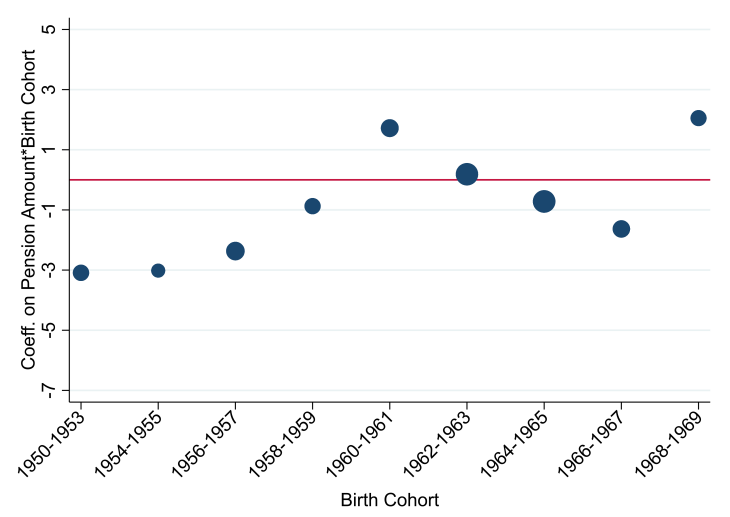

(b) Full set of controls

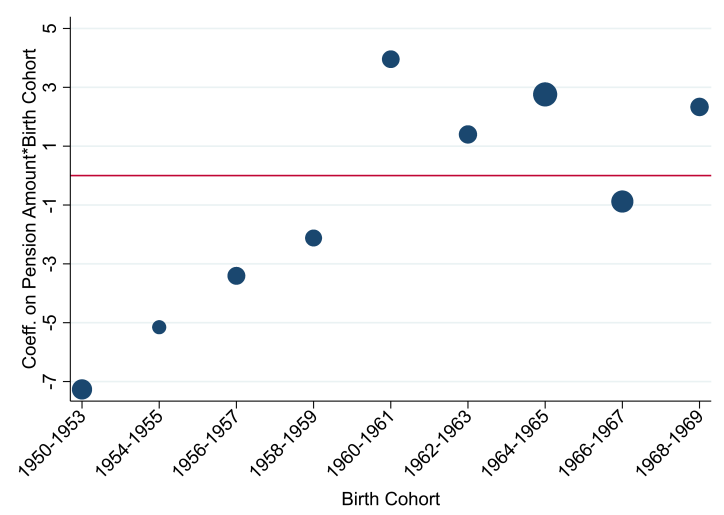

The graphs plot $\gamma_{k}$, the coefficient on the interaction between InitialPension ${ }_{c}$ and a dummy for cohort $k$ or $k-1$, in the cohort specification without and with the full set of controls (urban, wealth, access to services, cost of children, AIDS, U5 mortality, maternal education). We pool together cohorts $k$ and $k-1$ to increase precision. Given the small number of women born before 1953, we pool together 1950-51 and 1952-53. Size of dots proportional to $1 /$ s.e. 
Figure 6: Mechanism - change in stopping behaviors
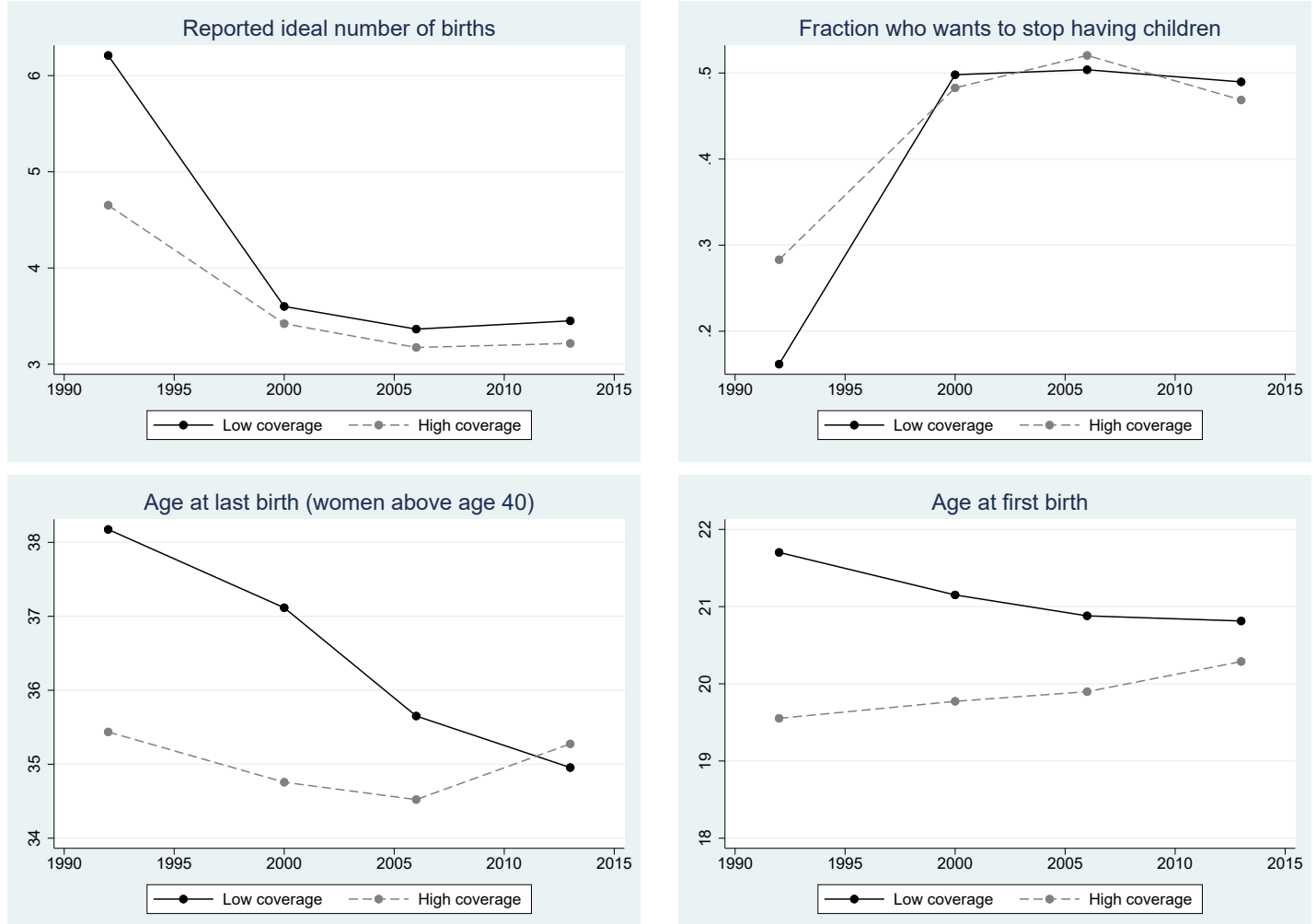

The graphs show the evolution of ideal number children (top left), proportion of women who want to stop having children (top right), age at last birth (bottom left) and age at first birth (bottom right) in regions with low (North) and high (Northeast and South) initial coverage. 
Table 1: Variation in pension benefits across ethnic groups

\begin{tabular}{lcccc}
\hline \hline & $\begin{array}{c}\text { Pension } \\
\text { per } \\
\text { month } \\
(1)\end{array}$ & $\begin{array}{c}\text { Ratio to } \\
\text { poverty } \\
\text { line } \\
(2)\end{array}$ & $\begin{array}{c}\text { Ratio to } \\
\text { average } \\
\text { income } \\
(3)\end{array}$ & $\begin{array}{c}\text { Fraction } \\
\text { of } \\
\text { population } \\
(4)\end{array}$ \\
\hline Before the extension & & & & \\
White & $\mathrm{R} 382$ & 7.0 & 1.26 & $6 \%$ \\
Coloured & $\mathrm{R} 192$ & 3.5 & 0.63 & $6.5 \%$ \\
Baster & $\mathrm{R} 150$ & 2.8 & 0.50 & $1 \%$ \\
Twsana & $\mathrm{R} 100$ & 1.8 & 0.33 & $0.5 \%$ \\
Damara & $\mathrm{R} 75$ & 1.4 & 0.25 & $10 \%$ \\
Herero; Nama & $\mathrm{R} 65$ & 1.2 & 0.21 & $12 \%$ \\
Owambo; Kavango; Caprivi & $\mathrm{R} 55$ & 1 & 0.18 & $64 \%$ \\
\hline After the extension & & & & \\
All & $\mathrm{R} 160$ & 3 & 0.50 & $100 \%$ \\
\hline \hline
\end{tabular}

The table shows the official amount of social pensions paid to different ethnic groups, in absolute terms and relative to the poverty line and the average income, before (1989) and after (1996) the Pension Act. Source: Devereux (2001). 
Table 2: Variation in pension coverage across regions

\begin{tabular}{|c|c|c|c|c|}
\hline & \multicolumn{2}{|c|}{$\begin{array}{l}\text { Fraction of recipients } \\
\text { among eligible people }\end{array}$} & \multirow{2}{*}{$\begin{array}{c}\text { Fraction of } \\
\text { population } \\
(3)\end{array}$} \\
\hline & & $\begin{array}{l}\text { All } \\
(1)\end{array}$ & $\begin{array}{l}\text { Blacks only } \\
\text { (2) }\end{array}$ & \\
\hline \multicolumn{5}{|c|}{ Before the extension } \\
\hline \multirow{2}{*}{$\begin{array}{l}\text { South } \\
\text { region }\end{array}$} & Hardap & $78 \%$ & $48 \%$ & $4.7 \%$ \\
\hline & Karas & $76 \%$ & $61 \%$ & $4.4 \%$ \\
\hline \multirow{5}{*}{$\begin{array}{l}\text { Central } \\
\text { region } \\
\text { Northeast } \\
\text { region }\end{array}$} & Erongo & $72 \%$ & $57 \%$ & $3.8 \%$ \\
\hline & *Khomas & $66 \%$ & $15 \%$ & $11.9 \%$ \\
\hline & Caprivi & $65 \%$ & $65 \%$ & $6.3 \%$ \\
\hline & Omaheke & $60 \%$ & $52 \%$ & $3.7 \%$ \\
\hline & Otjozondjupa & $48 \%$ & $36 \%$ & $7.2 \%$ \\
\hline \multirow{6}{*}{$\begin{array}{l}\text { North } \\
\text { region }\end{array}$} & Kunene & $51 \%$ & $45 \%$ & $4.6 \%$ \\
\hline & Oshikoto & $49 \%$ & $46 \%$ & $9.1 \%$ \\
\hline & Kavango & $39 \%$ & $38 \%$ & $8.4 \%$ \\
\hline & Ohangwena & $36 \%$ & $35 \%$ & $12.8 \%$ \\
\hline & Omusati & $34 \%$ & $34 \%$ & $13.6 \%$ \\
\hline & Oshana & $31 \%$ & $31 \%$ & $9.5 \%$ \\
\hline \multicolumn{2}{|l|}{ Namibia } & $49 \%$ & $37 \%$ & $100 \%$ \\
\hline \multicolumn{5}{|c|}{ After the extension } \\
\hline \multicolumn{2}{|c|}{ Namibia } & $88 \%$ & $\mathrm{n} / \mathrm{a}$ & $100 \%$ \\
\hline
\end{tabular}

The table shows the effective coverage of social pensions in different regions, before (1993-94) and after (1998) the outsourcing of pension delivery, for all ethnic groups and for Blacks only. ${ }^{*}$ Khomas is the region of the capital city, Windhoek.

Source: all ethnic groups: Subbarao (1998); Blacks in 1993-94: own computation based on the assumption that the coverage for Whites was 100\% (see Figure A.4 in Appendix for more details). 
Table 3: Descriptive statistics before the extension of pensions

\begin{tabular}{|c|c|c|c|c|c|c|}
\hline \multirow[b]{3}{*}{ Panel A: Individual characteristics } & \multicolumn{3}{|c|}{ All } & \multicolumn{3}{|c|}{ Blacks only } \\
\hline & $\begin{array}{c}\text { High } \\
\text { coverage } \\
(1)\end{array}$ & $\begin{array}{c}\text { Low } \\
\text { coverage } \\
(2)\end{array}$ & $\begin{array}{c}\text { Khomas } \\
\text { (3) }\end{array}$ & $\begin{array}{c}\text { High } \\
\text { coverage } \\
(4)\end{array}$ & $\begin{array}{c}\text { Low } \\
\text { coverage } \\
(5)\end{array}$ & $\begin{array}{c}\text { Khomas } \\
\text { (6) } \\
\end{array}$ \\
\hline & & & & & & \\
\hline \multicolumn{7}{|l|}{ Ethnicity } \\
\hline \% European/Afrikaans & 0.21 & 0.03 & 0.27 & - & - & - \\
\hline \% Damara & 0.24 & 0.04 & 0.16 & 0.31 & 0.04 & 0.22 \\
\hline$\%$ Herero & 0.15 & 0.03 & 0.13 & 0.19 & 0.03 & 0.18 \\
\hline \% Owambo/Kavango/Caprivi & 0.40 & 0.90 & 0.43 & 0.50 & 0.93 & 0.60 \\
\hline \multicolumn{7}{|l|}{ Panel B: Regional controls } \\
\hline$\%$ poor & 0.29 & 0.35 & 0.08 & 0.34 & 0.35 & 0.10 \\
\hline$\%$ with at least primary education & 0.68 & 0.61 & 0.85 & 0.64 & 0.60 & 0.82 \\
\hline$\%$ econ. active in agriculture & 0.35 & 0.54 & 0.03 & 0.41 & 0.55 & 0.03 \\
\hline$\%$ living in urban areas & 0.45 & 0.14 & 0.87 & 0.39 & 0.12 & 0.83 \\
\hline$\%$ with hospital/clinic $>1$ hour-walk & 0.44 & 0.51 & 0.15 & 0.49 & 0.52 & 0.14 \\
\hline \% 5-14 ever in school & 0.88 & 0.91 & 0.93 & 0.86 & 0.91 & 0.92 \\
\hline \% 10-14 economically active & 0.05 & 0.06 & 0.00 & 0.06 & 0.06 & 0.00 \\
\hline$\%$ with bank/saving account & 0.46 & 0.26 & 0.70 & 0.41 & 0.24 & 0.67 \\
\hline Prevalence of HIV & 0.10 & 0.08 & 0.07 & 0.11 & 0.08 & 0.07 \\
\hline Infant mortality rate & 0.046 & 0.058 & 0.050 & 0.041 & 0.058 & 0.043 \\
\hline Observations & 20,324 & 9,088 & 2,586 & 16,935 & 8,937 & 1,876 \\
\hline
\end{tabular}

Data: NHIES 1993-94. The table describes important variables, separately for regions with low (North) initial pension coverage, regions with high (Northeast, South and Erongo) initial pension coverage and the region of the capital city Khomas. In the first three columns, all ethnic groups are included. In the last three columns, only Blacks are included. The sample of interest for our analysis excludes Whites and Khomas, and corresponds to columns 4 and 5 . 
Table 4: Fertility trends, before, during and after the extension, by initial pensions

\begin{tabular}{lc}
\hline \hline \multicolumn{2}{c}{ Linear annual trend in birth rate } \\
\hline Before extension (1990-1992) & -0.00285 \\
& $(0.00435)$ \\
During extension (1992-1997) & $-0.00769^{* * *}$ \\
& $(0.00104)$ \\
After extension (1997-2012) & -0.00065 \\
& $(0.00046)$ \\
Before $\times$ InitialPension & -0.00004 \\
& $(0.00004)$ \\
During $\times$ InitialPension & $0.01646^{* *}$ \\
& $(0.00766)$ \\
After $\times$ InitialPension & 0.00006 \\
& $(0.00350)$ \\
\hline Observations & 141637 \\
Clusters & 35 \\
\hline \hline
\end{tabular}

We estimate the linear annual trend in birth rate separately for three periods: 1990-1992, 1992-1997, and 1997-2012. 1992 to 1997 is the period of transition from the old pension system, with unequal benefits and coverage, to the new system, with equalized replacement rate and universal coverage. InitialPension is the expected annual pension for a given ethnic group in a given region before the extension, in thousand rands $(\min =0.2 ; \max =0.585)$. Sample: women aged 15 to 40 in year $t$; White ethnic group and Khomas region are excluded. Data: DHS. OLS regression. Standard errors are clustered at the region*ethnicity level. Significance levels : ${ }^{*} \mathrm{p}<0.10,{ }^{* *} \mathrm{p}<0.05,{ }^{* * *} \mathrm{p}<0.01$. 


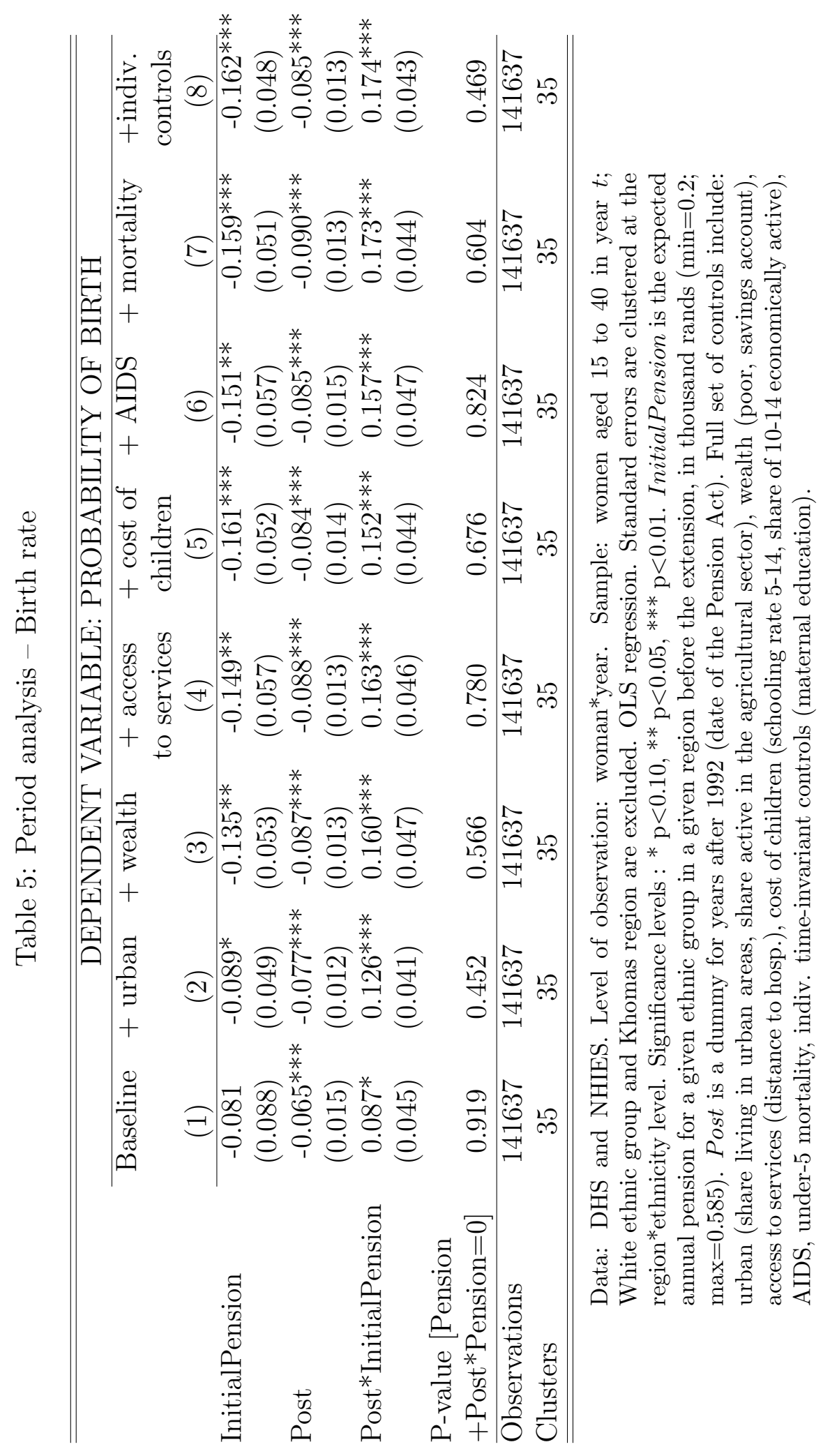


Table 6: Cohort analysis - Completed fertility

\begin{tabular}{|c|c|c|}
\hline \multirow[b]{3}{*}{$\begin{array}{l}\text { Panel A } \\
\text { Pre-post analysis (1950-55; 1965-69) }\end{array}$} & \multicolumn{2}{|c|}{ DEP VAR: NUMBER OF BIRTHS } \\
\hline & $\begin{array}{l}\text { Baseline } \\
\quad(1)\end{array}$ & $\begin{array}{l}\text { Full set of controls } \\
\qquad(2)\end{array}$ \\
\hline & & \\
\hline InitialPension & $\begin{array}{l}-2.873 \\
(2.207)\end{array}$ & $\begin{array}{l}-6.097 * * * \\
(1.474)\end{array}$ \\
\hline Exposure & $\begin{array}{l}-2.507^{* * *} \\
(0.503)\end{array}$ & $\begin{array}{l}-2.883^{* * *} \\
(0.460)\end{array}$ \\
\hline Exposure*InitialPension & $\begin{array}{r}2.703^{*} \\
(1.580)\end{array}$ & $\begin{array}{l}5.690^{* * *} \\
(1.479)\end{array}$ \\
\hline P-value Pension & & \\
\hline+ Exposure ${ }^{*}$ Pension $=0$ & 0.675 & 0.924 \\
\hline Observations & 901 & 901 \\
\hline Clusters & 26 & 26 \\
\hline $\begin{array}{l}\text { Panel B } \\
\text { Partial analysis (1950 to } 1969)\end{array}$ & & \\
\hline InitialPension & $\begin{array}{l}-2.371 \\
(1.899)\end{array}$ & $\begin{array}{l}-4.626^{* * *} \\
(1.099)\end{array}$ \\
\hline Exposure & $\begin{array}{l}-2.423^{* * *} \\
(0.512)\end{array}$ & $\begin{array}{l}-2.689^{* * *} \\
(0.407)\end{array}$ \\
\hline Exposure*InitialPension & $\begin{array}{r}2.947^{*} \\
(1.502)\end{array}$ & $\begin{array}{l}5.390^{* * *} \\
(1.270)\end{array}$ \\
\hline $\begin{array}{l}\text { P-value Pension } \\
+ \text { Exposure*Pension }=0\end{array}$ & 0.766 & 0.508 \\
\hline Observations & 1798 & 1798 \\
\hline Clusters & 28 & 28 \\
\hline
\end{tabular}

Data: DHS and NHIES. Level of observation: woman. Sample: women aged 44 to 50 in wave $w$; White ethnic group and Khomas region are excluded; cohorts 1950-55 and 1965-69 in Panel A; cohorts 1950 to 1969 in Panel B. OLS regression. Standard errors are clustered at the region*ethnicity level. Significance levels : ${ }^{*} \mathrm{p}<0.10,{ }^{* *} \mathrm{p}<0.05,{ }^{* * *} \mathrm{p}<0.01$. InitialPension is the expected annual pension for a given ethnic group in a given region before the extension, in thousand rands $(\min =0.2 ; \max =0.585)$. Exposure $=$ $\max (\min (10 ; k-1955) ; 0) / 10$ for cohort $k$ and varies from 0 (before 1955) to 1 (after 1965). Full set of controls include: urban (share living in urban areas, share active in the agricultural sector), wealth (poor, savings account), access to services (distance to hosp.), cost of children (schooling rate 5-14, share of 10-14 economically active), AIDS, U5 mortality, indiv. time-invariant controls (maternal education). 


\section{Appendix}

Figure A.1: Fertility and pensions in the world
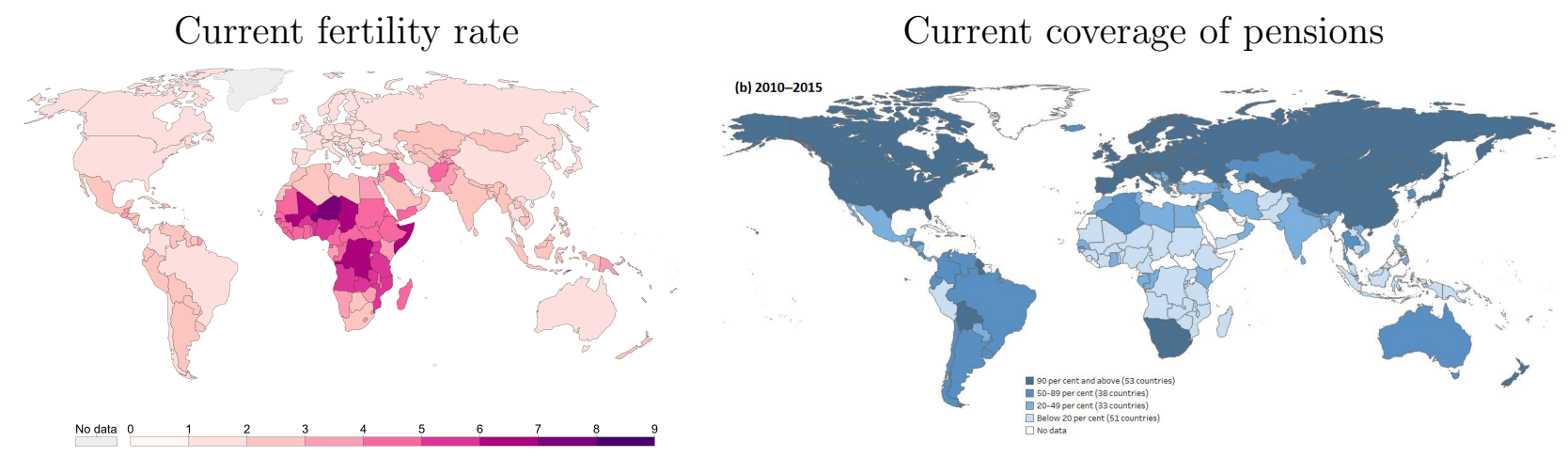

The map on the left shows the average number of births per woman in 2017, based on estimates from United Nations (2017). Link: https://ourworldindata.org/grapher/children-born-per-woman?year=2017

The map on the right shows the percentage of the population above statutory pensionable age receiving any type of old-age pension in 2010-15, based on estimates from International Labour Organization (2018). Link: http://www.social-protection.org/gimi/gess/RessourceDownload.action?ressource.ressourceId=54657

Figure A.2: Current social pension systems in Sub-Saharan Africa

Coverage

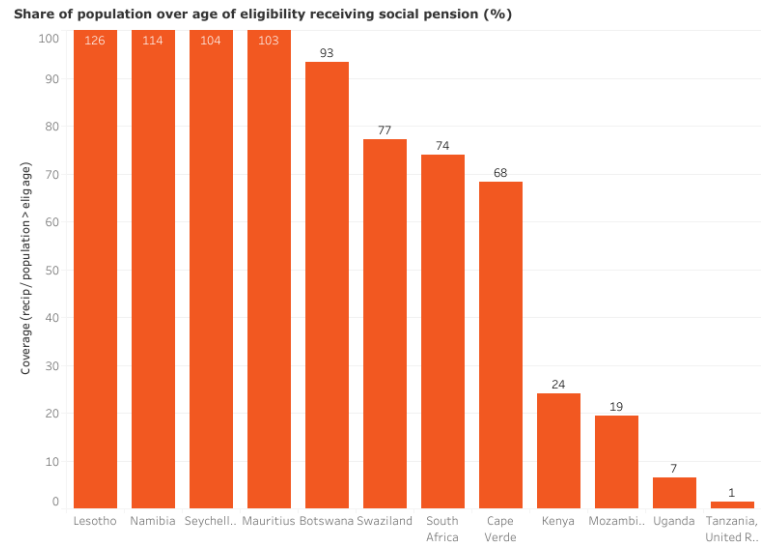

Replacement rate

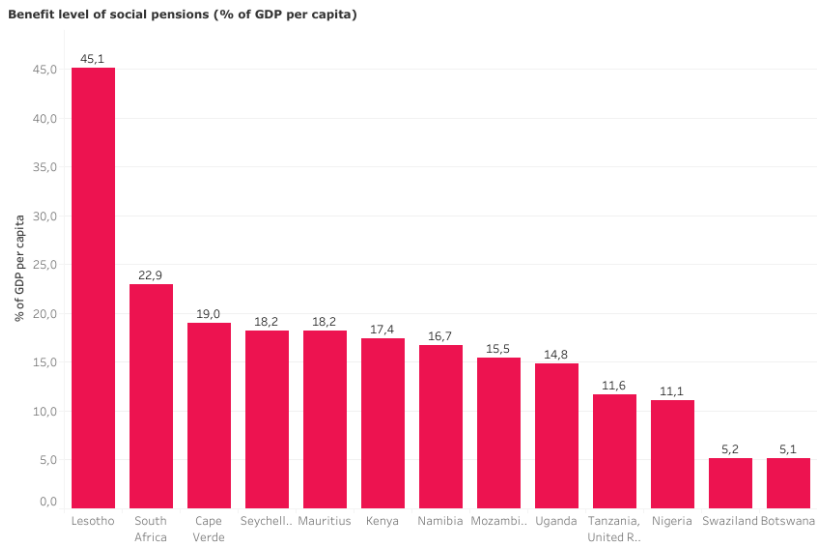

The graph on the left shows the share of population over age of eligibility receiving social pensions. The graph on the right shows the benefit level of social pensions as a percentage of GDP per capita. Countries that are not listed do not have a social pension system. Source: pension-watch.net, 2019 
Figure A.3: Initial coverage predicts change in coverage by region

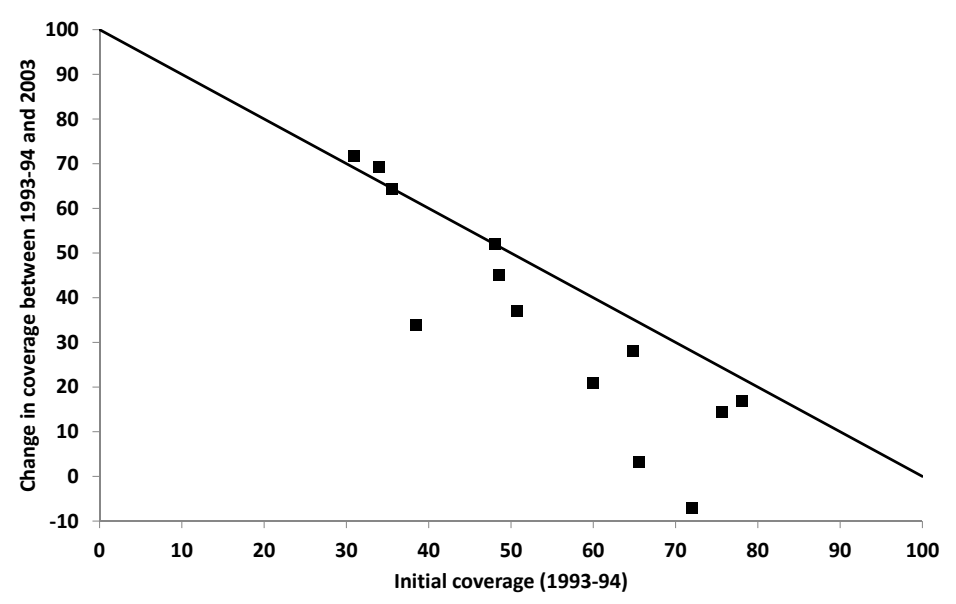

The graph plots the coverage in 1993-94 on the x-axis and the change in coverage between 1993-94 and 2003 on the y-axis. Each dot is a region. The line $y=100-x$ represents the attainment of universal coverage between the two periods. Source: own computation based on Subbarao (1998) and Levine, van den Berg, and $\mathrm{Yu}(2011)$ 
Figure A.4: Initial coverage partly reflects fraction of Whites in the population

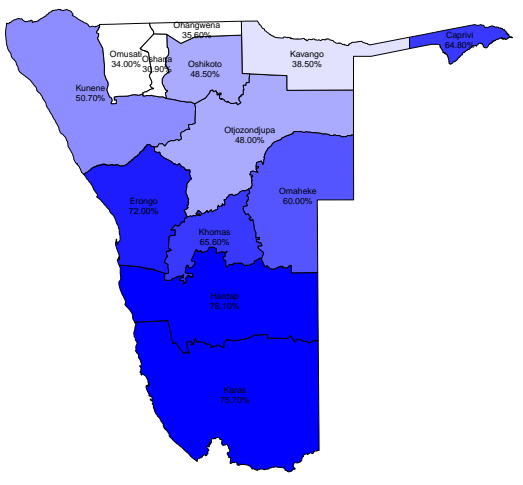

Initial coverage (all)

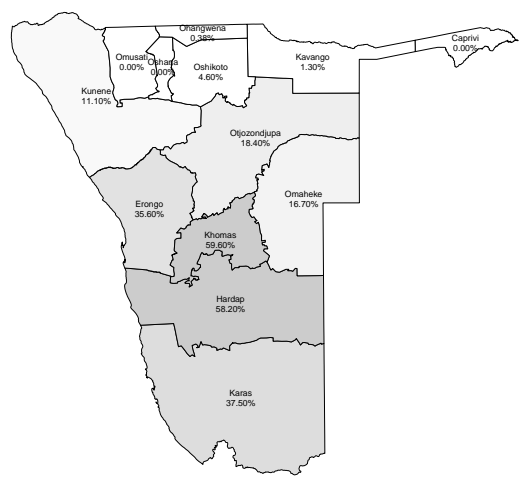

Fraction of Whites

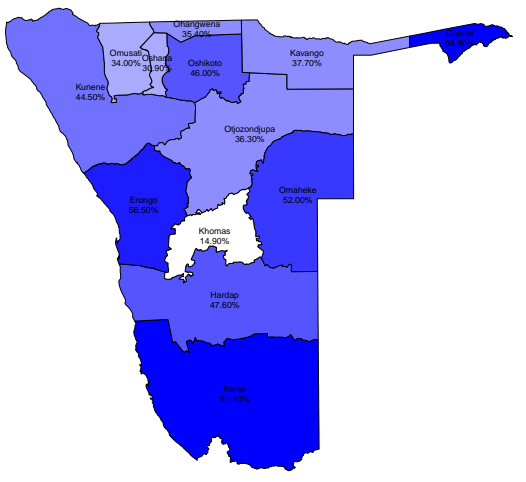

Initial coverage, excluding Whites

The map on the top left shows the initial coverage for the whole population, by region, according to Subbarao (1998). The map on the top right shows the fraction of Whites among people above age 60, by region, computed using NHIES 1993-94. The map on the bottom shows the estimated initial coverage for Blacks only, by region, computed under the assumption that the coverage for Whites is $100 \%$. 
Figure A.5: Pre-trends: catch-up in fertility rate did not start before the extension

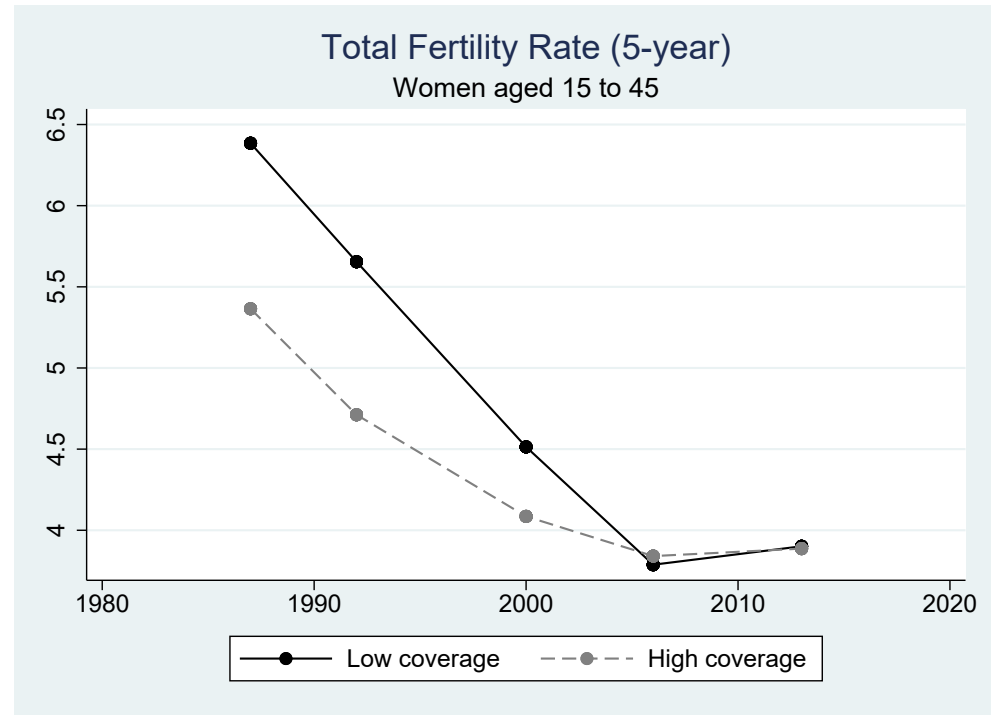

The graph shows the evolution of Total Fertility Rates in regions with low (North, in black) and high (Northeast and South, in grey) initial pension coverage. The extension of pensions took place between 1992 and 1997. The Total Fertility Rate is a synthetic rate measuring how many births a woman would have if she was subject to current age-specific fertility rates at all ages throughout her reproductive life. Source: own computation based on age-specific birth rates in the five years preceding each survey. To compute the rate in 1987, we use retrospective information provided in the 1992 wave and covering the 1982-1987 period. Since women above 45 in 1982-1987 were not interviewed in 1992, we also exclude that age group in later waves to ensure consistency. Sample: women aged 15 to 45, non-Whites. Data: DHS. 
Figure A.6: Confounders: other drivers of fertility tend to diverge during the extension
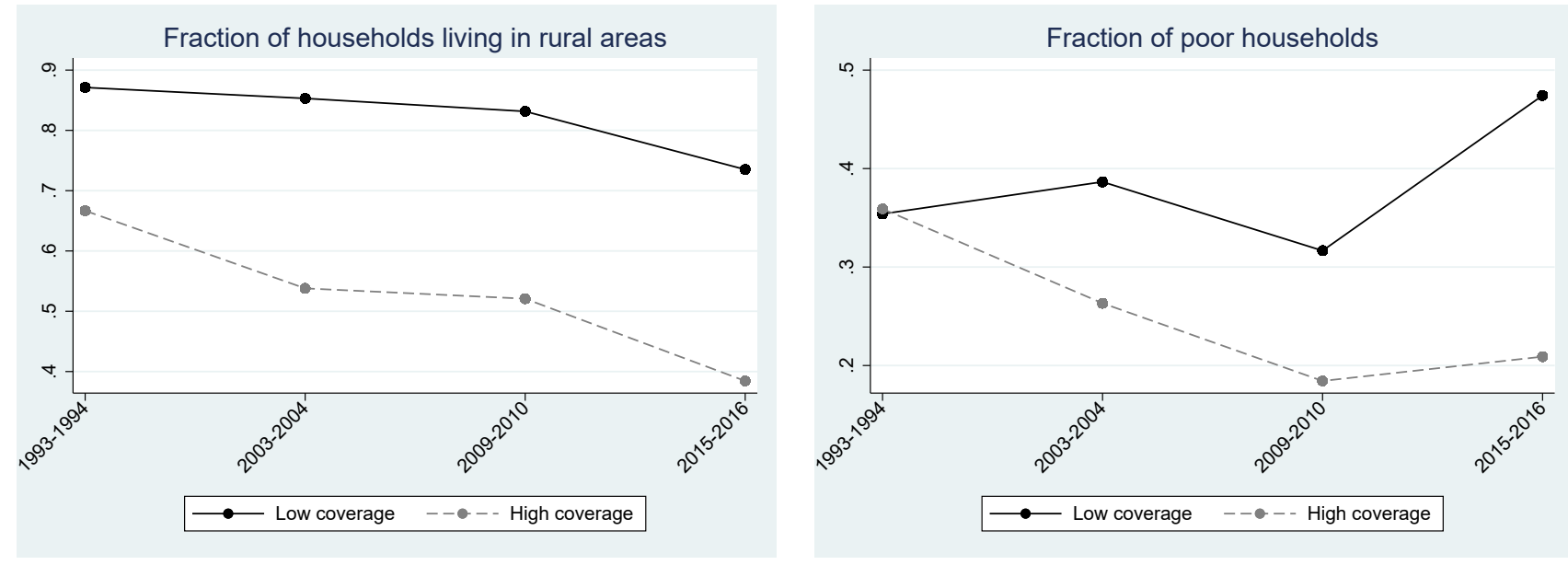

The graphs show the evolution of the fraction of rural (on the left) and poor (on the right) households in regions with low (North) and high (Northeast and South) initial pension coverage. The extension of pensions took place between 1992 and 1997. Sample: non-Whites. Data: NHIES. 
Figure A.7: Robustness: catch-up in fertility is not driven by migration
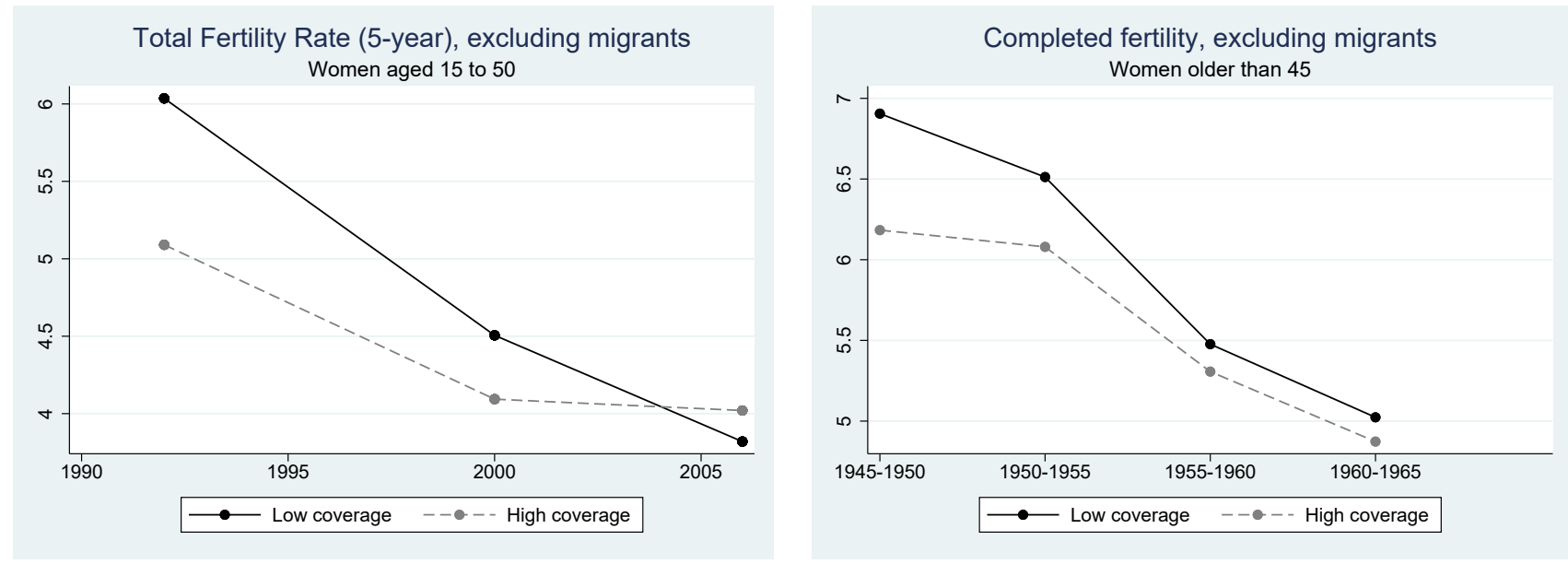

The graphs show the evolution of the 5-year total fertility rate (on the left) and completed fertility (on the right) in regions with low (North) and high (Northeast and South) initial pension coverage. We exclude people who migrated in the 10 years preceding the survey. Information on the migration status was not collected in the last DHS wave (2013). See Figure 1 for more details.

Figure A.8: Robustness: difference-in-differences coefficients with mother fixed effects

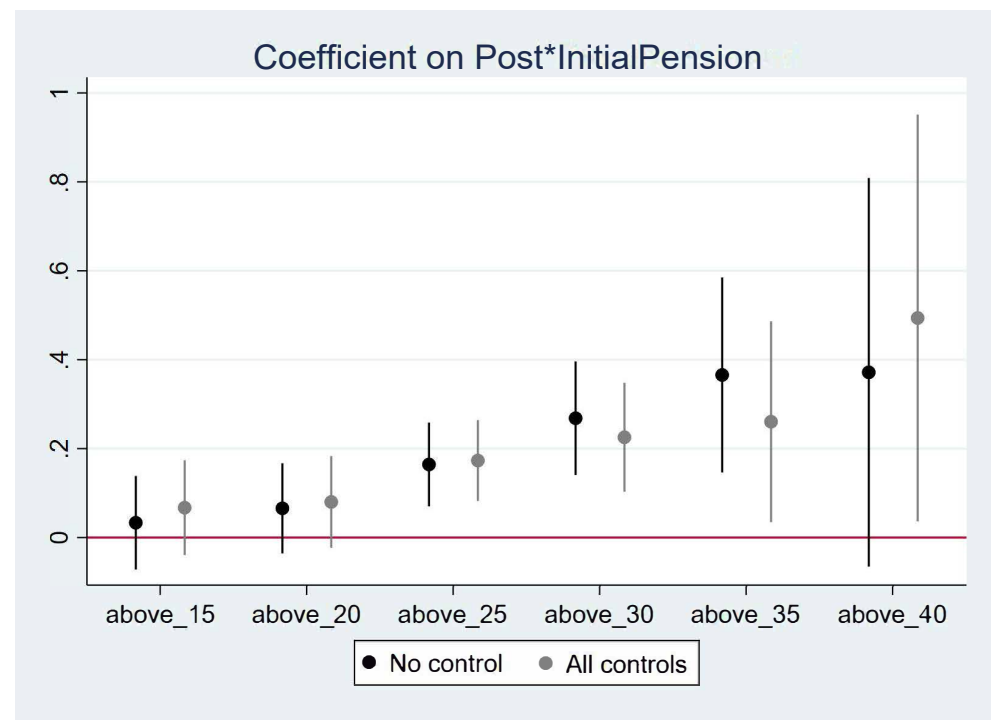

The graph plots $\gamma$, the coefficient on the interaction between InitialPension ${ }_{c}$ and Post $t_{t}$ in Equation 1 with mother fixed effects, controlling or not for a restricted set of controls (urban and wealth), for women above age $a$ in 1992. The vertical lines represent the confidence intervals at $95 \%$. 
Figure A.9: Mechanisms: rule out changes in female labor and ability to control
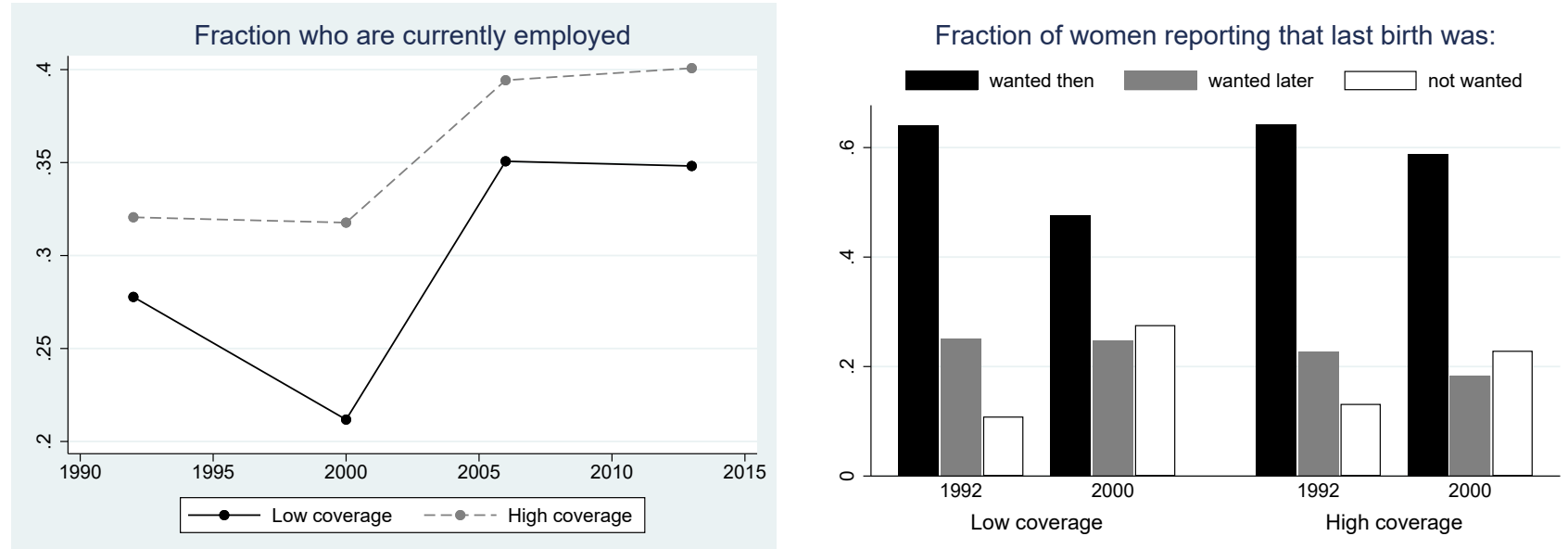

The graph on the left shows the evolution of the fraction of women currently employed in regions with low (North) and high (Northeast and South) initial pension coverage. Women are considered as unemployed if they answered that their occupation is "not working" or "self-employed in agriculture". We aggregated these two categories to make sure that answers are comparable across waves. Women working on fields without receiving any payment in kind or in cash were registered as "self-employed in agriculture" in 2006 and as "not working" in the other waves. Data: DHS.

The graph on the right shows the evolution of the fraction of births wanted then (black bars), wanted later (grey bars) and not wanted (white bars) in regions with low (North) and high (Northeast and South) initial pension coverage, before (1992) and after (2000) the extension of pensions. Data: DHS. 
Table A.1: Fertility trends: Whites and Khomas have different pre- and post-trends

\begin{tabular}{lcc}
\hline \hline Sample & $\begin{array}{c}\text { Include Whites } \\
\text { and Khomas } \\
(1)\end{array}$ & $\begin{array}{c}\text { Exclude Whites, } \\
\text { include Khomas } \\
(2)\end{array}$ \\
\hline Before extension (1990-1992) & -0.00553 & -0.00200 \\
& $(0.00436)$ & $(0.00473)$ \\
During extension (1992-1997) & $-0.01297^{* * *}$ & $-0.00861^{* * *}$ \\
& $(0.00230)$ & $(0.00114)$ \\
After extension (1997-2012) & -0.00021 & -0.00017 \\
Before $\times$ Whites & $(0.00118)$ & $(0.00034)$ \\
During $\times$ Whites & $-0.00003^{* * *}$ & \\
& $(0.00001)$ & \\
After $\times$ Whites & $0.00311^{*}$ & \\
Before $\times$ Khomas & $(0.00163)$ & \\
During $\times$ Khomas & 0.00025 & $-0.00002^{* *}$ \\
After $\times$ Khomas & $(0.00073)$ & $(0.00001)$ \\
& & 0.00405 \\
& & $-0.00352)$ \\
Observations & & $(0.00048)$ \\
Clusters & & 155774 \\
\hline \hline
\end{tabular}

We estimate the linear annual trend in birth rate separately for three periods: 1990-1992, 1992-1997, and 1997-2012. 1992 to 1997 is the period of transition from the old pension system, with unequal benefits and coverage, to the new system, with equalized replacement rate and universal coverage. Whites is a dummy for people defined as White, Coloured or Baster during the apartheid regime. Khomas is a dummy for the region of the capital city. Sample: women aged 15 to 40 in year $t$; Whites are excluded in column (2). Data: DHS. OLS regression. Standard errors are clustered at the region*ethnicity level. Significance levels : * $\mathrm{p}<0.10,{ }^{* *} \mathrm{p}<0.05,{ }^{* * *} \mathrm{p}<0.01$. 


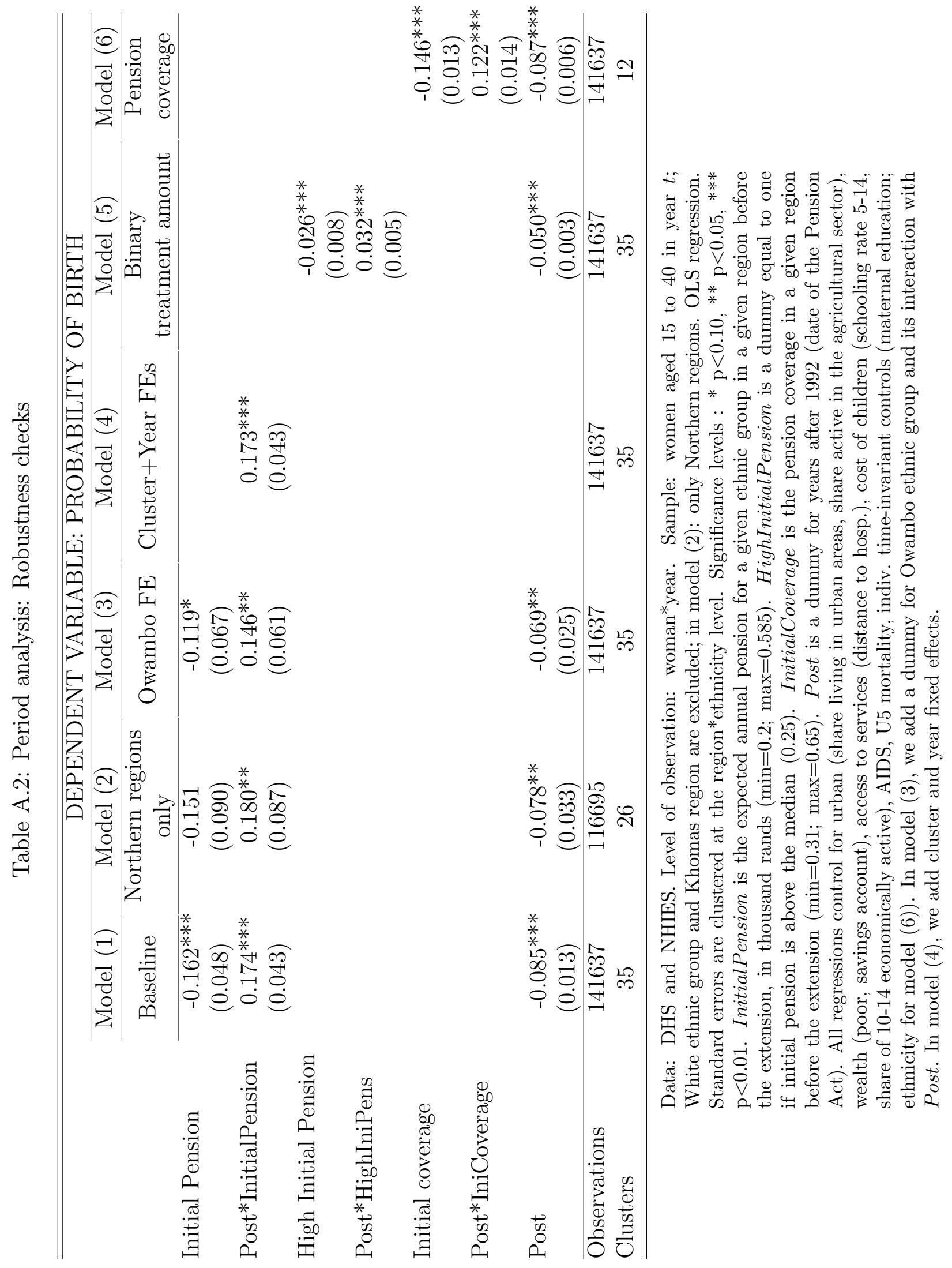




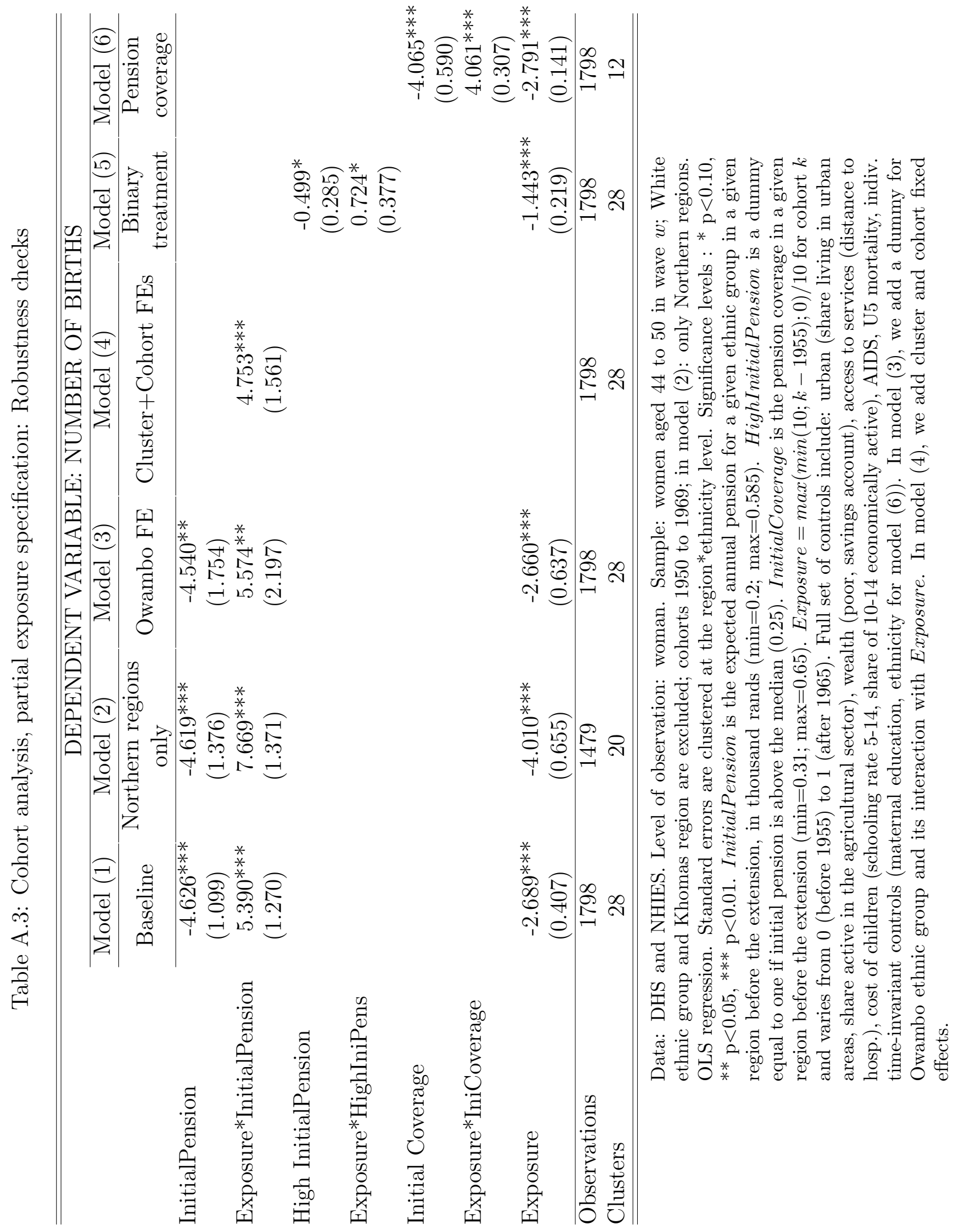


Table A.4: Separating income and insurance channels: heterogeneity by co-residence with an elderly

\begin{tabular}{lcccc}
\hline \hline & \multicolumn{4}{c}{ DEP VAR: PROBABILITY OF BIRTH } \\
\cline { 2 - 5 } & \multicolumn{2}{c}{ Lives with no elderly } & \multicolumn{2}{c}{ Lives with an elderly } \\
& No control & All controls & No control & All controls \\
& $(1)$ & $(2)$ & $(3)$ & $(4)$ \\
\cline { 2 - 5 } InitialPension & -0.131 & $-0.226^{* * *}$ & -0.036 & $-0.105^{* *}$ \\
& $(0.080)$ & $(0.062)$ & $(0.166)$ & $(0.041)$ \\
Post & $-0.078^{* * *}$ & $-0.111^{* * *}$ & -0.050 & $-0.045^{* * *}$ \\
& $(0.023)$ & $(0.017)$ & $(0.047)$ & $(0.012)$ \\
Post*InitialPension & $0.111^{*}$ & $0.240^{* * *}$ & 0.093 & $0.094^{* *}$ \\
& $(0.061)$ & $(0.056)$ & $(0.134)$ & $(0.042)$ \\
P-value [Pension & & & & \\
+Post*Pension=0] & 0.342 & 0.775 & 0.451 & 0.511 \\
\hline Observations & 107302 & 107302 & 34335 & 34335 \\
Clusters & 35 & 35 & 29 & 29 \\
\hline \hline
\end{tabular}

Data: DHS and NHIES. Level of observation: woman*year. Sample: women aged 15 to 40 in year $t$; White ethnic group and Khomas region are excluded; the sample is split between households without and with at least member older than 60. OLS regression. Standard errors are clustered at the region*ethnicity level. Significance levels : ${ }^{*} \mathrm{p}<0.10,{ }^{* *} \mathrm{p}<0.05,{ }^{* * *} \mathrm{p}<0.01$. InitialPension is the expected annual pension for a given ethnic group in a given region before the extension, in thousand rands $(\min =0.2 ; \max =0.585)$. Post is a dummy for years after 1992 (date of the Pension Act). Controls: urban (share living in urban areas, share active in the agricultural sector), wealth (poor, savings account), access to services (distance to hosp.), cost of children (schooling rate 5-14, share of 10-14 economically active), AIDS, under-5 mortality, indiv. time-invariant controls (maternal education). 
Table A.5: Testing for non-linearities

\begin{tabular}{lcc}
\hline \hline \multirow{2}{*}{ Dep. var. } & $\begin{array}{c}\text { Period specification } \\
\text { Probability of birth } \\
(1)\end{array}$ & $\begin{array}{c}\text { Cohort specification } \\
\text { Number of births } \\
(2)\end{array}$ \\
\cline { 2 - 3 } Low Initial Pension & $0.029^{* *}$ & $0.983^{* *}$ \\
High Initial Pension & $(0.013)$ & $(0.446)$ \\
& 0.007 & 0.373 \\
Post1992 & $(0.016)$ & $(0.557)$ \\
& $-0.015^{*}$ & \\
Post*LowInitialPension & $(0.008)$ & \\
Post*HighInitialPension & $-0.032^{* * *}$ & \\
& $(0.010)$ & -0.475 \\
Exposure & -0.005 & $(0.360)$ \\
& $(0.016)$ & $-1.023^{* *}$ \\
Exposure*LowInitialPension & & $(0.439)$ \\
& & -0.079 \\
Exposure*HighInitialPension & & $(0.573)$ \\
& & Yes \\
Controls & & 1798 \\
Observations & & 28 \\
Clusters & 141637 & \\
\hline \hline
\end{tabular}

Data: DHS and NHIES. Level of observation: woman*year in first column, woman in second column. Sample: women aged 15 to 40 in year $t$ in first column, women aged 44 to 50 in wave $w$ in second column; White ethnic group and Khomas region are excluded. Using the continuous InitialPension variable, we created three categories: Low, Medium and High initial pension, consisting of groups with an average expected pension of respectively 0.25 thousand rands (corresponding to a coverage between 30 and 40\%), 0.35 thousand rands (coverage between 40 and 50\%) and 0.45 thousand rands (coverage between 50 and 60\%). Medium initial pension is the omitted category. Post is a dummy for years after 1992 (date of the Pension Act). OLS regression. Standard errors are clustered at the region*ethnicity level. Significance levels : ${ }^{*} \mathrm{p}<0.10,{ }^{* *}$ $\mathrm{p}<0.05,{ }^{* * *} \mathrm{p}<0.01$. Controls: urban (share living in urban areas, share active in the agricultural sector), wealth (poor, savings account), access to services (distance to hosp.), cost of children (schooling rate 514, share of 10-14 economically active), AIDS, under-5 mortality, indiv. time-invariant controls (maternal education).

If the impact of pension was linear, we should get difference-in-differences estimates of opposite sign on Low and High dummies with a magnitude roughly equal to $10 \%$ of the coefficient on the continuous variable (because the difference between Low and Medium pension (resp. High and Medium pension) is roughly equal to -0.1 (resp. +0.1) thousand rands). Specifications with a continuous pension variable predict that an increase by 1 thousand rands reduces the annual probability of birth by 0.17 and completed fertility by 5.4 children. Under a linearity assumption, the regressions with categorical variables should give coefficients around $-/+0.017$ in the period specification and $-/+0.54$ in the cohort specification. Instead, we find small and insignificant coefficients on the High dummy, whereas coefficients on the Low dummy are twice as large as expected. 